\title{
Measurement of Peroxiredoxin Activity
}

\author{
Kimberly J. Nelson ${ }^{1}$ and Derek Parsonage ${ }^{1}$ \\ ${ }^{1}$ Department of Biochemistry, Wake Forest University School of Medicine, Winston-Salem, \\ North Carolina
}

\begin{abstract}
Peroxiredoxins are cysteine-dependent peroxidases that react with hydrogen peroxide, larger hydroperoxide substrates, and peroxynitrite. Protocols are provided to measure Prx activity with peroxide by (1) a coupled reaction with NADPH, thioredoxin reductase, and thioredoxin, (2) the direct monitoring of thioredoxin oxidation, (3) competition with horseradish peroxidase, and (4) peroxide consumption using the FOX assay. Curr. Protoc. Toxicol. 49:7.10.1-7.10.28. (C) 2011 by John Wiley \& Sons, Inc.

Keywords: antioxidants $\bullet$ antioxidant enzymes $\bullet$ sulfenic acids $\bullet$ hydrogen peroxide $\bullet$ hydroperoxides $\bullet$ thiol peroxidase $\bullet \operatorname{Prx} \bullet \operatorname{PRDX} \bullet$ cysteine oxidation $\bullet$ redox catalysis $\bullet \mathrm{HRP} \bullet \mathrm{FOX}$
\end{abstract}

\section{INTRODUCTION}

Peroxiredoxin (Prx) enzymes (EC 1.11.1.15) are a family of cysteine-dependent peroxidases that react with hydrogen peroxide, aliphatic and aromatic hydroperoxide substrates, and peroxynitrite (Hall et al., 2010), as described in UNIT 7.9. These antioxidant enzymes are ubiquitous and highly expressed in many organisms, including plants, bacteria, and animals, where they can comprise up to $1 \%$ or more of cellular proteins (Winterbourn, 2008). It has been suggested that Prx proteins are responsible for the reduction of more than $90 \%$ of intracellular peroxide in humans (Winterbourn, 2008; Cox et al., 2010). Prxs are critical components of the antioxidant defense systems of many bacteria (Seaver and Imlay, 2001; Parsonage et al., 2008) and are important components in the plant chloroplast (Dietz et al., 2006). In eukaryotes, Prxs have been implicated in the regulation of a variety of signaling processes including cell proliferation, differentiation, and cell death (Veal et al., 2007). Because Prxs are induced by oxidative stress, highly expressed in various cancers, and linked to decreased sensitivity to radiation therapy (Zhang et al., 2005), these proteins are considered possible prognostic or therapeutic targets (Kang et al., 2005).

Interest in Prx enzymes has recently increased with the realization that these proteins react with a range of hydroperoxides with high catalytic rate constants on the order of $\sim 10^{7} \mathrm{M}^{-1} \mathrm{sec}^{-1}$ (Parsonage et al., 2005; Ogusucu et al., 2007; Peskin et al., 2007; Manta et al., 2009; Horta et al., 2010). The importance of Prx proteins was slow to be recognized, largely because early assays dramatically underestimated this rate, for two reasons. First, in many cases, reduction of the Prx is rate limiting; only with the development of the assays described in this chapter (Basic Protocols 2 and 3) was it possible to measure the true peroxide-dependent rate of Prxs (Parsonage et al., 2005; Ogusucu et al., 2007). Second, early assays often used hydrogen peroxide concentrations around $1 \mathrm{mM}$ and, under these conditions, many Prxs react with a second molecule of peroxide to form a cysteine sulfinic acid $\left(-\mathrm{SO}_{2} \mathrm{H}\right)$. In the absence of a specialized repair protein such as sulforedoxin, the sulfinic acid form is irreversibly inactivated (Lowther et al., 2010). The half-life of human Prx 2 is just $20 \mathrm{sec}$ in the presence of $1 \mathrm{mM}$ hydrogen peroxide and reductant (Rabilloud et al., 2002; Yang et al., 2002). These results highlight how important it is to carefully design and implement any kinetic assay with Prxs.
Assessment of the Activity of Antioxidant Enzymes

7.10.1

Supplement 49 
This chapter includes four protocols that have been used with some success to characterize one or more Prx. Basic Protocol 1 provides a general absorbance-based assay in which Prx activity is coupled to oxidation of NADPH via thioredoxin reductase (TrxR) and thioredoxin (Trx). Basic Protocol 2 is an adaptation of this assay that allows for the measurement of a true peroxide-dependent rate and directly monitors the changes to Trx fluorescence as Trx becomes oxidized. Basic Protocol 3 measures the second-order rate constant of Prx reacting with hydrogen peroxide by monitoring the ability of Prx to prevent peroxide from reacting with horseradish peroxidase. Basic Protocol 4 utilizes the ferrous oxidation-xylenol orange (FOX) assay, which directly measures peroxidedependent oxidation of $\mathrm{Fe}$ (II) to $\mathrm{Fe}(\mathrm{III})$.

All of the assays described here, with the exception of Alternate Protocol 3, utilize purified protein. In order to obtain sufficient quantities for these assays, the Prx of interest will typically be recombinantly expressed in and purified from E. coli. Details of expression and purification will have to be determined separately for each protein prior to starting the assays. Physiologically, Prxs detoxify peroxides at the expense of either NADPH or NADH. In most cell types, hydrogen peroxide disappearance is also catalyzed by catalase and glutathione peroxidase, making it difficult, if not impossible, to measure in vivo Prx activity with any specificity. Alternate Protocol 3 provides one example of an in vivo assay and avoids this difficulty by using the FOX assay to measure the disappearance of cumene hydroperoxide, which is a good substrate for most Prxs and not readily reduced by either catalase or glutathione peroxide. All of these assays, with the exception of Basic Protocol 3, can be used with lipid hydroperoxides such as linoleic acid hydroperoxide (Baker et al., 2001). Although the protocols presented can be adapted to utilize peroxynitrite, this substrate is treated in more detail elsewhere (Trujillo et al., 2008).

\section{STRATEGIC PLANNING}

We provide a starting set of assays and concentrations that have been used successfully to measure Prx activity. However, because Prxs utilize a range of reductants and exhibit a wide range of rates, the most appropriate assay will need to be selected based on the characteristics of each individual protein (see Critical Parameters for more information), and assays will almost certainly have to be adapted to fit individual situations. It is also suggested that some time be spent prior to setting up the assays to identify some critical characteristics of the Prx. In particular, it will be helpful to identify the Prx subfamily, the genomic context of the Prx of interest, and the possible reductants present in the native environment; more details about these characteristics are provided in Critical Parameters.

NOTE: Purified Prx proteins are typically stored $\sim 10 \mathrm{mg} / \mathrm{ml}$ and can be stored at $-80^{\circ}$ or $-20^{\circ} \mathrm{C}$ (without freeze-thaw cycles) for an indefinite period of time.

BASIC PROTOCOL 1

\footnotetext{
Measurement of Peroxiredoxin Activity
}

\subsection{0 .2}

\section{MEASUREMENT OF NADPH-DEPENDENT PEROXIREDOXIN ACTIVITY IN PRESENCE OF Trx, TrxR, AND PEROXIDE}

Although some Prxs are reduced physiologically by specialized disulfide reductases, Trx is the most common reductant. This protocol describes a general assay for Trx-linked Prx activity. Prx is assayed by coupling its activity to oxidation of NADPH via TrxR (Fig. 7.10.1), as occurs physiologically. The reaction as described here is carried out in a conventional, thermostat-controlled spectrophotometer and can be used with a variety of peroxide substrates. For this assay, care must be taken to optimize the concentrations of the various components so that the assay is limited as little as possible by the reduction of Trx by TrxR and NADPH. The concentrations listed here have been used with success previously, but care must be taken to ensure that they are appropriate for each situation. Although it is preferable to utilize the Trx and TrxR system from the same organism as the Prx to be studied, we have found that E. coli Trx and TrxR often reduce Prxs from 
other bacterial species with similar kinetic parameters as their native $\operatorname{Trx} / \operatorname{TrxR}$ system (Baker et al., 2001; Parsonage et al., 2010a).

\section{Materials}

Prx reaction buffer (see recipe)

Purified Trx (500 $\mu \mathrm{M}$ diluted in Prx reaction buffer); E. coli and human purified Trx and are commercially available from multiple sources or can be overexpressed and purified from E. coli (Wollman et al., 1988; Lennon and Williams, 1995) — following this protocol, $1 \mathrm{mg}$ Trx will be sufficient for $\sim 301$-ml assays

Purified E. coli TrxR ( $50 \mu \mathrm{M}$ diluted in Prx reaction buffer); E. coli and mammalian purified TrxR are commercially available from multiple sources or can be overexpressed and purified from E. coli (see Poole et al., 2000, for $E$. coli, and Rengby et al., 2009, for rat)—following this protocol, $0.1 \mathrm{mg} \operatorname{TrxR}$ will be sufficient for $\sim 301$-ml assays

$10 \mathrm{mM}$ peroxide solution: hydrogen peroxide (see recipe), cumene hydroperoxide (see recipe), or $t$-butyl hydroperoxide (see recipe)

$15 \mathrm{mM}$ NADPH (dissolved in $10 \mathrm{mM}$ Tris $\cdot \mathrm{SO}_{4}, \mathrm{pH} 8.5$ )

Peroxiredoxin (Prx; $50 \mu \mathrm{M}$ diluted into Prx reaction buffer); in order to obtain sufficient quantities for these assays, the Prx of interest will typically be recombinantly expressed in and purified from $E$. coli (details of expression and purification will have to be determined separately for each protein prior to starting the assays)

Spectrophotometer with kinetic capabilities (required) and temperature regulation (preferred; i.e., with an attached water bath)

1-ml semi-micro quartz cuvettes

\section{Establish conditions for Prx-dependent assay}

1. Turn on the spectrophotometer and set the water bath to $25^{\circ} \mathrm{C}$; allow them to warm up and become stable $(\sim 30 \mathrm{~min})$. Set the spectrophotometer to kinetics mode with a wavelength of $340 \mathrm{~nm}$.

2. In a 1-ml quartz cuvette, mix Prx reaction buffer, $10 \mu \mathrm{l}$ Trx, $10 \mu \mathrm{l}$ TrxR, and various peroxide concentrations between 15 and $500 \mu \mathrm{M}(100 \mu \mathrm{M}$ peroxide is a good choice for initial assays). Add Prx reaction buffer for a total of $980 \mu \mathrm{l}$. Place the cuvette in the spectrophotometer and allow for thermal equilibration (3 to $5 \mathrm{~min}$ ).

Final concentrations in the assay should be $5 \mu M \operatorname{Trx}$ and $0.5 \mu M \operatorname{Tr} x$ R.

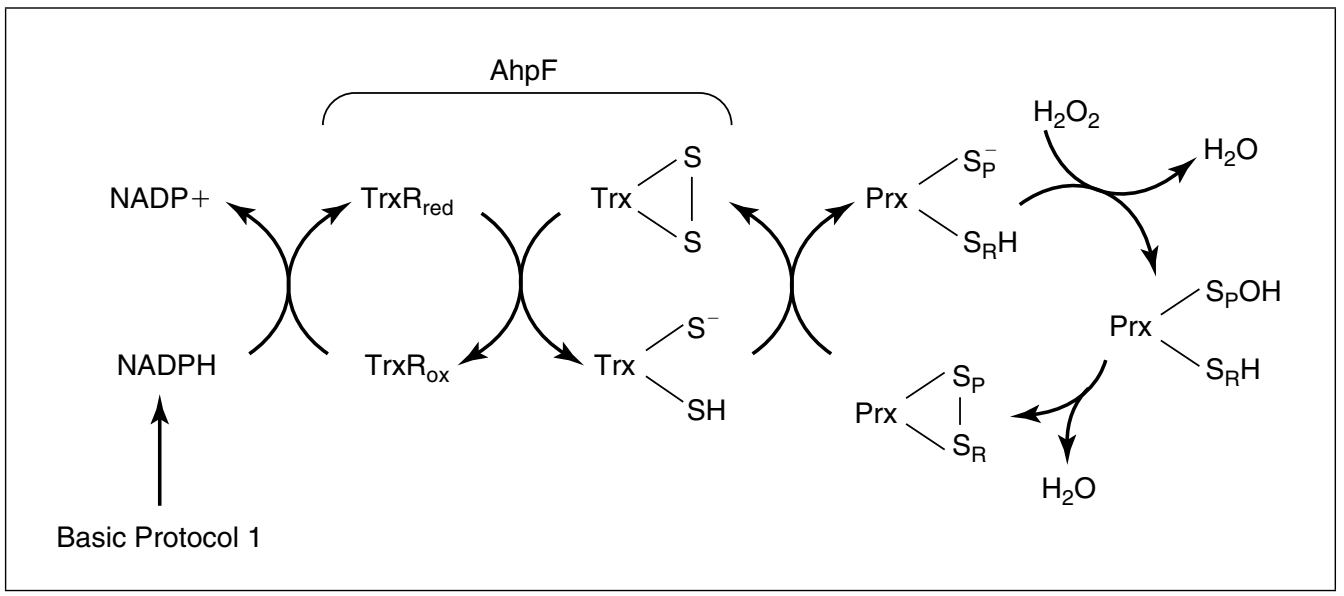

Figure 7.10.1 Determination of Prx activity in the presence of NADPH, Trx, and TrxR. The peroxidatic cysteine in $\operatorname{Prx}\left(-S_{\mathrm{P}}{ }^{-}\right)$reacts with peroxide to form a cysteine sulfenic acid (Prx$\mathrm{S}_{\mathrm{P}} \mathrm{OH}$ ) which, in 2-Cys Prxs, then forms a disulfide bond with the resolving cysteine $\left(\mathrm{S}_{\mathrm{R}} \mathrm{H}\right)$. The Prx disulfide is reduced by Trx with electrons ultimately coming from NADPH through TrxR. As described in Basic Protocol 1, Prx turnover is monitored as a change in absorbance at $340 \mathrm{~nm}$ as NADPH becomes oxidized. For bacterial AhpC-like proteins, AhpF can replace both Trx and TrxR.

Assessment of the Activity of Antioxidant Enzymes

7.10.3

Supplement 49 
3. Add $10 \mu \mathrm{l}$ of $15 \mathrm{mM}$ NADPH for a final concentration of $150 \mu \mathrm{M}$ and an $A_{340}$ reading of $\sim 0.9$. Mix the contents and begin recording the 340-nm absorbance, which will provide the background rate of peroxide reaction with Trx and TrxR. Monitor until a steady reading, or a linear decrease, is established ( $\sim 1 \mathrm{~min})$; make sure that no more than $10 \%$ of the NADPH is used up at this step (an approximate 1 AU decrease).

4. Add $10 \mu \mathrm{l}$ of a $50 \mu \mathrm{M}$ Prx solution to start the assay (final concentration of $0.5 \mu \mathrm{M}$ ). Monitor the change in absorbance at $340 \mathrm{~nm}$ for 1 to $2 \mathrm{~min}$, ensuring that $<10 \%$ to $20 \%$ of the NADPH has been oxidized.

In general, assays should be designed so that Trx levels are roughly 10-fold higher than Prx and TrxR concentrations to ensure that Prx peroxidase activity is rate limiting, and not electron transfer to either Trx or Prx.

5. From the difference in rate before and after the addition of Prx, calculate the Prxdependent rate of NADPH oxidation $\left(\varepsilon_{340}=6,220 \mathrm{M}^{-1} \mathrm{~cm}^{-1}\right)$. Only measure the initial, linear portion of the curve.

6. Repeat steps 2 to 5 using $1 \mu \mathrm{M}$ Prx. Test to ensure that the rate is approximately twice the rate with $0.5 \mu \mathrm{M}$ Prx.

7. Repeat steps 2 to 5 using $0.25 \mu \mathrm{M}$ Prx. Test to ensure that the rate is approximately half of the rate with $0.5 \mu \mathrm{M}$ Prx.

8. If altering Prx concentrations (steps 6 to 7 ) does not change the activity proportionately, adjust the Trx and TrxR concentrations so that it does.

If the assay is correctly set up, increasing the TrxR concentration should not increase the rate.

\section{Measure rates for Prx turnover with peroxide}

9. Once the conditions have been established, repeat steps 2 to 5 using different peroxide concentrations between 15 and $500 \mu \mathrm{M}$. Fit the rates at each peroxide concentration to the Michaelis-Menten equation to find the apparent $K_{\mathrm{m}}$ for peroxide under these conditions; ideally, the final peroxide concentrations should range from one fifth to five-fold the $K_{\mathrm{m}}$ for peroxide substrate. Determine the preliminary $K_{\mathrm{m}}$ for peroxide and adjust the range of peroxide concentrations for all future measurements as appropriate.

If peroxide concentrations below $15 \mu \mathrm{M}$ are required, it may be useful to decrease the concentration of all assay components and measure the reaction for a longer period of time to ensure that $\sim 10 \%$ of the NADPH is used during the course of the assay and the signal is large enough to be reliably measured. Alternatively, increased sensitivity may be obtained by measuring changes to NADPH fluorescence rather than absorbance. See Baker et al. (2001) for more details.

\section{Measure rates for Prx turnover with Trx}

10. Repeat steps 2 to 5 using a different concentration of Trx.

Ideally, the apparent $V_{\text {max }}$ should start to saturate as the Trx concentration increases. As the Trx concentration increases, the apparent $K_{m}$ for peroxide may also increase and it may require higher peroxide concentrations to saturate the reaction.

11. Plot the data using a linearized form of the Michaelis-Menten equation.

We typically use a Hanes-Woolf plot which plots [peroxide] on the $x$ axis and [peroxide]/rate on the y axis (Fig. 7.10.2A) because this type of plot does not exaggerate the error at low substrate concentrations as is often observed with Lineweaver-Burk plots. A Hanes-Woolf plot should result in a series of straight lines, each one corresponding to a set of experiments carried out at one Trx concentration.

Measurement of 
A

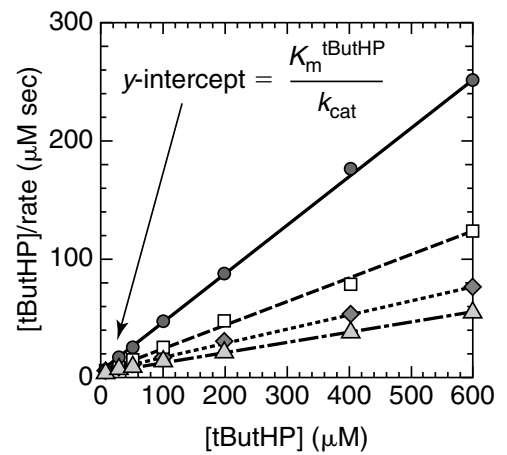

[tButHP] $(\mu \mathrm{M})$
B

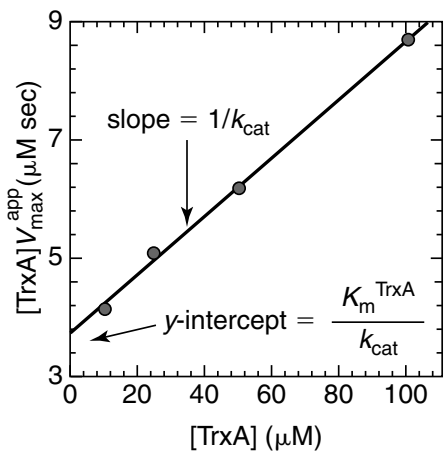

C

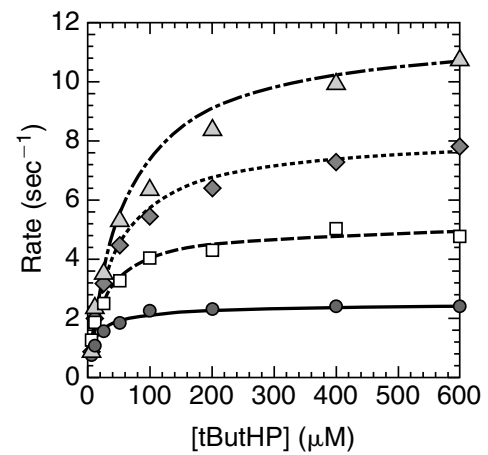

[tButHP] $(\mu \mathrm{M})$

Figure 7.10.2 Kinetic analysis to determine rate constants for Treponema pallidum AhpC with Escherichia coli TrxA and $t$-butyl hydroperoxide (tButHP). (A) The data for all substrate concentrations were plotted according to the Hanes-Woolf representation of the Michaelis-Menten equation to obtain the apparent $V_{\max }$ values (1/slope) for each TrxA concentration. (B) A secondary Hanes-Woolf plot was generated with [TrxA] on the $x$ axis and $[\operatorname{TrxA}] / V_{\max }^{\mathrm{app}}$ on the $y$ axis to obtain the true $k_{\text {cat }}$ and $K_{\mathrm{m}}{ }^{\text {TrA }}$ values. The true $k_{\text {cat }}$ value obtained from plot $\mathrm{B}$ can then be used to calculate the $K_{\mathrm{m}}^{\mathrm{tButHP}}$ using the $y$ intercept in plot $A$. (C) All of the data shown in plots $A$ and $B$ can be fit globally using the multi-function nonlinear regression capabilities of a computer program such as Sigmaplot (Systat Software).

The point of intersection of the lines indicates the appropriate kinetic mechanism to use for data analysis. When lines intersect on the y-axis, this suggests a substituted enzyme (ping-pong) mechanism, where the first substrate (i.e., peroxide) reacts and dissociates prior to binding of the second substrate (i.e., Trx), which reacts, dissociates, and returns the enzyme to its starting state. The Prx family members studied so far fit best to a pingpong mechanism. When the lines of the Hanes-Woolf plot intersect to the left of the $y$ axis, this suggests the formation of a ternary complex, in which both substrates must bind prior to undergoing the chemical reaction. For more information about these different mechanisms see Cornish-Bowden (2004).

12. As the reciprocal slope for each Trx concentration provides the apparent $V_{\max }$ for each Trx concentration, generate secondary Hanes-Woolf plots with [Trx] on the $x$ axis and $[\operatorname{Trx}] / V_{\max }^{\mathrm{app}}$ on the $y$ axis to obtain the true $k_{\mathrm{cat}}$ and the true $K_{\mathrm{m}}$ value for $\operatorname{Trx}$ (Fig. 7.10.2B).

As an alternative to steps 11 to 12, all of the data can be fit globally (Fig. 7.10.2C) as described in Basic Protocol 2, step 27. Dalziel analysis has also been used to obtain similar rate constants for Prx proteins ( for details refer to Baker et al., 2001; Jaeger et al., 2004; Sayed and Williams, 2004).

\section{MEASURING PEROXIDASE ACTIVITY WITH AhpF AS REDUCTANT}

Bacterial Prxs of the AhpC/Prx1 subfamily frequently have a dedicated flavoprotein reductant, AhpF; in these cases, the AhpF gene is found immediately downstream of the coding sequence for the AhpC it reduces. Functionally, AhpF is a fusion of a Trx-like Nterminal domain to a C-terminal TrxR-like domain (Poole et al., 2000, Wood et al., 2001). Unlike TrxR, which prefers NADPH, AhpF typically utilizes NADH. AhpC activity with $\mathrm{AhpF}$ is assayed using a similar procedure to that described in Basic Protocol 1, except that $0.1 \mu \mathrm{M}$ AhpF replaces both the Trx and TrxR, and $150 \mu \mathrm{M}$ NADH replaces NADPH in the assay. Starting conditions for the assay should utilize final concentrations of $0.1 \mu \mathrm{M}$

ALTERNATE PROTOCOL 1

Assessment of the Activity of Antioxidant Enzymes

7.10 .5

Supplement 49 
AhpF, $0.5 \mu \mathrm{M}$ AhpC, and $100 \mu \mathrm{M}$ peroxide in $50 \mathrm{mM}$ potassium phosphate $\mathrm{pH} 7.0,1 \mathrm{mM}$ EDTA, $100 \mathrm{mM}$ ammonium sulfate.

AhpF isolated from Salmonella typhimurium, Streptococcus mutans, and Amphibacillus xylanus have significant NADH oxidase activity, as oxygen can readily react directly with the reduced FAD cofactor of these enzymes (Poole, 2005). It is important to measure this background rate prior to the addition of AhpC. The background rate should be subtracted from the measured rate obtained after Prx addition to calculate the final AhpC-dependent rate.

BASIC

\section{PROTOCOL 2}

\section{MEASUREMENT OF PEROXIDE-DEPENDENT PEROXIREDOXIN ACTIVITY WITH EXCESS Trx (BY MONITORING Trx OXIDATION)}

Although the assay described in Basic Protocol 1 is most representative of the physiological activity of Prxs, it is frequently unable to distinguish the specificity for various peroxides because it is limited by the rate at which electrons can be passed from NADPH through TrxR and Trx to reduce the Prx (Poole and Ellis, 1996; Parsonage et al., 2010b). The assay described in this section has been designed to overcome this limitation by using a high concentration of pre-reduced Trx (Fig. 7.10.3). In many Trx proteins, at least one tryptophan (Trp) residue near the catalytic CXXC motif is appropriately oriented to act as a fluorescent reporter of the active site redox state (Trp31 in E. coli Trx; Krause and Holmgren, 1991; Parsonage et al., 2010b). Because of this, Trx oxidation can be monitored directly as a decrease in fluorescence.

Although it is theoretically possible to use this assay with a standard fluorimeter possessing kinetic capabilities, many Prxs have been shown to have a very low $K_{\mathrm{m}}$ for peroxide $(\sim 1 \mu \mathrm{M}$ in the case of $S$. typhimurium AhpC and hydrogen peroxide; Parsonage et al., 2005). Due to the low concentrations of substrate used in these cases, it is very difficult if not impossible to observe the linear initial rate with the typical initial dead time required for manual mixing. In order to overcome this problem, a stopped-flow spectrometer is typically used to follow the change in Trx fluorescence over the first $5 \mathrm{sec}$ after mixing with Prx and peroxide. This assay can be used with a variety of peroxide substrates.

Although many of the Trx proteins (including human and E. coli) are suitable for this assay, this is not always the case. For proteins such as AhpF and Grx, the conversion between disulfide and dithiol forms is spectrally silent or minimally detectable. In these cases, it is possible to engineer in a sensitive fluorescent reporter by substituting in a strategically located Trp (Parsonage et al., 2005, 2010b).

\section{Materials}

Purified E. coli Trx

Dithiothreitol (DTT)

Prx reaction buffer (see recipe)

Purified peroxiredoxin (Prx; typically stored at $\sim 10 \mathrm{mg} / \mathrm{ml}$ )

$10 \mathrm{mM}$ peroxide substrate: hydrogen peroxide (see recipe), cumene hydroperoxide (see recipe), or $t$-butyl hydroperoxide (see recipe)

Syringe-tip filters, 0.22 - or $0.45-\mu \mathrm{m}$

Spectrophotometer capable of measuring UV absorbance

Stopped-flow spectrophotometer, capable of measuring fluorescence with excitation at $280 \mathrm{~nm}$ and emission monitored at $>320 \mathrm{~nm}$

Software program with multifunction nonlinear regression capabilities (e.g., Sigmaplot from Systat Software, http://www.systat.com)

Additional reagents and equipment for prereduction of Trx (Support Protocol 1), protein assay (APPENDIX 3I) 


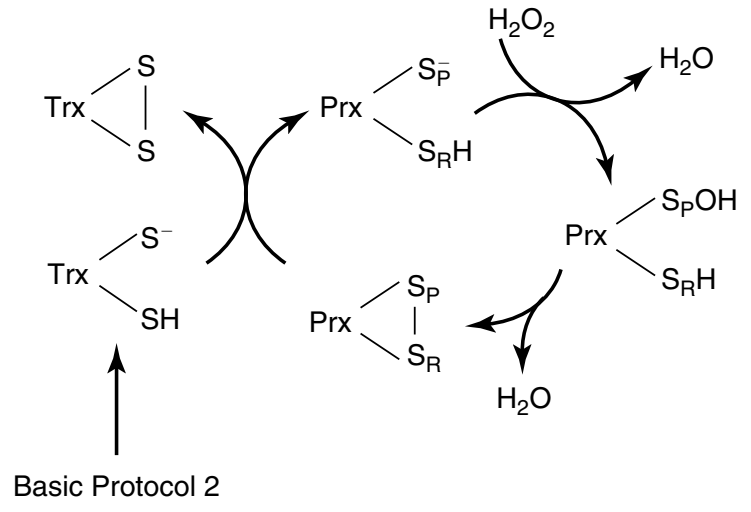

Figure 7.10.3 Determination of Prx activity by directly monitoring Trx oxidation. As described in Basic Protocol 2, Prx reacts with peroxide to form a sulfenic acid on the peroxidatic cysteine $\left(\mathrm{S}_{\mathrm{P}} \mathrm{OH}\right)$ and, ultimately, a disulfide bond. The fluorescence of Trx decrease as it becomes oxidized and reduces the Prx disulfide.

\section{Reduce Trx}

1. Prereduce $\sim 10 \mathrm{mg}$ of Trx using an approximately 20 -fold molar excess of DTT and remove excess DTT using a PD-10 desalting column (all procedures described in Support Protocol 1).

2. Combine the peak fractions and filter them through a $0.22-\mu \mathrm{m}$ or $0.45-\mu \mathrm{m}$ syringetip filter. Determine the concentration of the reduced Trx by measuring the $280-\mathrm{nm}$ absorbance of a dilution (typically, $50 \mu \mathrm{l}$ of Trx solution added to $600 \mu \mathrm{l}$ of buffer). Calculate the Trx concentration using the $\varepsilon_{280}\left(13,700 \mathrm{M}^{-1} \mathrm{~cm}^{-1}\right.$ for E. coli Trx; Holmgren and Reichard, 1967).

\section{Prepare a series of solutions containing Prx and reduced Trx}

3. Prepare a $\sim 25 \mu \mathrm{M}$ solution of Prx protein in Prx reaction buffer. If the extinction coefficient of the enzyme is known, use the diluted Prx from the cuvette to prepare the Prx plus Trx solutions. If the extinction coefficient is not known, perform a BCA protein assay (APPENDIX 3I) on the Prx solution to determine the concentration and then prepare a suitable dilution in Prx reaction buffer.

4. Prepare a series of solutions containing Prx and different Trx concentrations between 2.5 and $50 \mu \mathrm{M}$ (for example, 2.5, 5, 10,20, and $50 \mu \mathrm{M}$ final concentration after mixing in the stopped-flow). Make up each solution to a final volume of $7 \mathrm{ml}$ in Prx reaction buffer.

A typical starting concentration for this solution would be $20.2 \mu M \operatorname{Tr} x$ and $0.2 \mu M$ Prx. The reduced Trx will reduce the Prx, leaving $20 \mu M$ reduced Trx and $0.2 \mu M$ reduced Prx as the starting concentrations. Stopped-flow spectrophotometers typically mix equal volumes of reactants, so this solution should be prepared at twice the final desired protein concentration. After mixing with peroxide substrate in the stopped-flow, the final concentration of protein will be $10 \mu M$ Trx and $0.1 \mu M$ Prx.

5. Filter the Trx/Prx mixtures through a 0.22 - or $0.45-\mu \mathrm{m}$ syringe-tip filter.

\section{Prepare a series of peroxide dilutions}

6. Make multiple peroxide solutions in a final volume of $15 \mathrm{ml}$ Prx reaction buffer.

All solutions should be prepared at twice the final desired peroxide concentration. A minimum of $3 \mathrm{ml}$ is required for each set of reactions at one Trx concentration. Ideally, the final peroxide concentrations should range from one-fifth to five-fold the $K_{m}$ for peroxide substrate. Since the $K_{m}$ for a given Prx is initially unknown, prepare concentrations from

Assessment of the Activity of Antioxidant Enzymes

7.10 .7

Supplement 49 
1 to $500 \mu M$ (for example, 1, 2, 5, 10, 25, 50 100, 250, and $500 \mu M$ final concentrations). After examining the first set of results, determine the preliminary $K_{m}$ for peroxide and adjust the range of peroxide concentrations for all future measurements to appropriately cover the preliminary $K_{m}$.

7. Filter all peroxide dilutions using a $0.22-$ or 0.45 - $\mu \mathrm{m}$ syringe-tip filter.

\section{Prepare stopped-flow spectrophotometer}

You should be familiar with operation of the stopped-flow instrument before starting these experiments. This protocol assumes that the user is familiar with the setup and operation of the stopped flow instrument. It is advised that a new user seek the advice of someone familiar with the instrument before starting these assays.

8. Adjust the water bath to give a temperature of $25^{\circ} \mathrm{C}$ in the mixing chamber. Turn on the stopped-flow instrument and allow the lamp output, photomultiplier detector, and temperature of the water bath to stabilize for $1 \mathrm{hr}$.

9. Flush the instrument drive syringes, flow cell, and tubing with Prx reaction buffer. Set up the instrument to monitor fluorescence changes with an excitation wavelength of $280 \mathrm{~nm}$ and an emission wavelength $>320 \mathrm{~nm}$.

\section{Determine settings and fluorescence changes for each Trx concentration}

10. Leave reaction buffer in one drive syringe and load $\sim 2 \mathrm{ml}$ of one Prx/Trx solution in the other. Allow the solutions to equilibrate to the required temperature.

This usually happens quickly (in 3 to 5 min) in most instruments, since thermostatted water surrounds the drive syringes and mixing chamber.

11. Activate mixing between $\operatorname{Prx} / \operatorname{Trx}$ and reaction buffer to obtain the starting fluorescence of reduced $\operatorname{Trx}$ in the mixing chamber.

The stopped-flow spectrophotometer automatically injects only a portion of the solution in each syringe $(\sim 50 \mu \mathrm{l})$ in equal volumes into the mixing chamber, where the change in fluorescence is monitored. With each subsequent injection, the previous reaction is pushed out of the mixing chamber by new, equal-volume solutions from each syringe, resulting in a 2-fold reduction in the protein concentrations in the mixing chamber compared to the syringe solutions. Therefore, the same Prx/Trx solution can be maintained and used in one syringe, while multiple peroxide solutions are exchanged into the second syringe.

12. Set the instrument sensitivity by adjusting the photomultiplier (PMT) voltage so that the fluorescent signal is $80 \%$ of the maximum signal; this PMT voltage should be used for all reactions at the same Trx concentration. Monitor the signal for 10 to $20 \mathrm{sec}$ to observe any background rate.

Usually this background rate will be negligible, as Trx is a stable protein. If the background rate is significant, it will have to be subtracted from all rates measured in the presence of peroxide.

13. Replace the reaction buffer in the drive syringe with a peroxide concentration that is greater than the Trx concentration. Drive the reaction two times to ensure that the previous buffer has been fully flushed from the mixing chamber.

The peroxide concentration must be high enough to ensure that all the Trx is oxidized by the end of the reaction. A minimum of 3-ml volume should be used to load the drive syringe.

14. After allowing for thermal equilibration, set the timescale of the reaction to $20 \mathrm{sec}$ and start the instrument to mix enzymes and peroxide using a low sensitivity scale (the window showing the range of observed fluorescence changes should be zoomed out so that the whole reaction can be observed; Trx fluorescence will decrease as Trx becomes oxidized during the reaction of Prx with peroxide; Fig. 7.10.4); when the

\subsection{8}




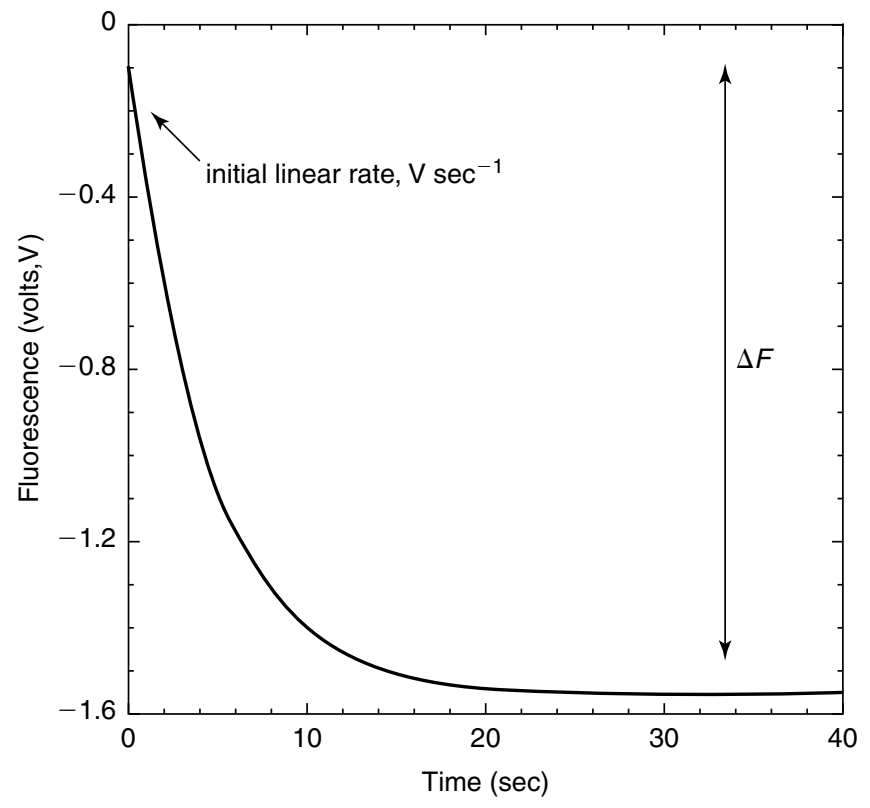

Figure 7.10.4 Thioredoxin fluorescence decreases during oxidation. The total fluorescence change $(\Delta F)$ in the presence of Prx and excess peroxide is used to convert the rate of change in fluorescence in $\mathrm{V} \mathrm{sec}-1$ into $\mu \mathrm{M}$ peroxide $\sec ^{-1} \mu \mathrm{M}^{-1}$ Prx using the equation: Rate ( $\mu \mathrm{M}$ peroxide $\left.\sec ^{-1} \mu \mathrm{M}^{-1} \mathrm{Prx}\right)=$ rate $\left(\mathrm{V} \mathrm{sec}{ }^{-1}\right) \cdot[\mathrm{Trx}] /(\Delta F \mathrm{x}[\mathrm{Prx}])$, where $[\mathrm{Trx}]$ and $[\mathrm{Prx}]$ are the final concentrations of thioredoxin and Prx respectively.

reaction is complete, the fluorescence signal will remain constant. If the reaction is not complete by the end of $20 \mathrm{sec}$, increase the observation time. Repeat the longest time course to confirm the magnitude of the total fluorescence change. Calculate the starting fluorescent signal by extrapolating the initial rate back to time zero. Record the value for the total fluorescence change $(\Delta F=$ starting fluorescence final fluorescence).

The total change in fluorescence during the reaction is important, as this value is used to convert the change in fluorescence signal to a rate of substrate depletion (see step 25). This calibration run can be used for all further measurements at this Trx concentration and PMT voltage.

\section{Measure rate of Prx reaction with peroxide}

15. Adjust the measurement time to examine the initial 2 to $5 \mathrm{sec}$ of the reaction.

16. Measure the fluorescence changes with the same peroxide concentration until you have at least three consistent traces. Note an initial (albeit brief at low peroxide concentrations) linear phase for the decrease in fluorescence of the reaction mixture (Fig. 7.10.4); the lowest peroxide concentrations may require more traces (up to 10 to 12) to obtain a trustworthy average. Use a more sensitive signal scale for these observations and zoom in on the initial signal, as only the first few seconds of the reaction need to be visible.

17. Discard the used peroxide solution from the drive syringe to minimize the risk of contamination by enzyme. Load the next concentration of peroxide into the drive syringe and allow 3 to 5 min for thermal equilibration.

Do not choose the peroxide solutions in order from high concentration to low, but "randomize" the order. This will prevent the creation of a systematic error. If going directly from a high to a very low concentration, rinse the syringe with reaction buffer before adding the second peroxide solution, to prevent carryover from the high-peroxide solution.

Assessment of the Activity of Antioxidant Enzymes

7.10 .9

Supplement 49 
18. While solutions are equilibrating, average the traces for the previous peroxide concentration. Use linear regression to calculate the initial rate $(v)$; units should be $\mathrm{V} \sec ^{-1}$ (i.e., volts per second). Record this number for each peroxide and Trx concentration.

At low peroxide concentrations $(<1 \mu M)$, a decrease in fluorescence may only be observed after the individual traces have been averaged.

19. Repeat steps 16 to 18 until all the concentrations of peroxide have been used to calculate rates of reaction with one Prx/Trx solution

It is useful to plot the calculated rates $\left(V \mathrm{sec}^{-1}\right)$ directly against the peroxide concentration as you perform the experiments. In this way, you can spot anomalous measurements, caused by incorrect dilution of substrate or instrument artifact. Bubbles accidentally introduced into the stopped-flow instrument can give spurious rates, and hence should be avoided. Also, this plot will quickly reveal if the correct peroxide concentration range has been covered. The plot should indicate approach to saturation at the higher peroxide concentrations, while measurements at the lowest peroxide concentrations will be significantly slower (see Fig. 7.10.2C).

\section{Measure rate of Prx reaction with next Trx concentration}

20. Once you have a satisfactory range of measurements, replace the Trx/Prx solution with one with the next Trx concentration.

21. For each new Trx concentration, remove the peroxide solution and rinse the syringe two to three times with buffer. Adjust the photomultiplier voltage and determine the full fluorescence change during the reaction as described in steps 10 to 14 .

Adjusting the photomultiplier voltage for each Trx concentration has the advantage that the instrumental sensitivity is increased for the lower Trx concentrations, making small fluorescence changes easier to observe.

22. Measure the reaction rate with each peroxide concentration as described in steps 15 to 19 .

23. Repeat for each Trx concentration.

\section{Measure rate of Trx reaction with peroxide (optional)}

If high peroxide concentrations $(>1 \mathrm{mM})$ are needed, you will need to perform blank reactions in the absence of Prx, as there will be non-negligible rates of Trx reacting directly with the peroxide substrate.

24. For these blank reactions, make solutions containing each concentration of Trx and no Prx. Use these solutions to perform steps 10 to 23.

\section{Analyze data}

25. Convert observed fluorescent change rates in $\mathrm{V} \mathrm{sec}^{-1}$ into the rate in $\mu \mathrm{M}$ peroxide $\sec ^{-1} \mu \mathrm{M}^{-1} \operatorname{Prx}$ :

$$
\text { Rate }\left(\mu \mathrm{M} \text { peroxide } \sec ^{-1} \mu \mathrm{M}^{-1} \operatorname{Prx}\right)=\operatorname{rate}\left(\mathrm{V} \mathrm{sec}^{-1}\right) \cdot \frac{[\operatorname{Trx}]}{(\Delta F \cdot[\operatorname{Prx}])}
$$

\section{Equation 7.10.1}

where $[\operatorname{Trx}]$ and $[\operatorname{Prx}]$ are the final micromolar concentrations of Trx and Prx respectively, and $\Delta F$ is the total Trx fluorescence change in the presence of excess peroxide (step 14) for the same Trx concentration as that being analyzed. 
26. Plot the data using a Hanes-Woolf plot as described in detail in Basic Protocol 1, step 11.

The Prx family members studied so far fit best to a ping-pong mechanism (also called a substituted-enzyme mechanism), and a the Hanes-Woolf plot should result in a series of straight lines, each one corresponding to a set of experiments carried out with varying peroxide concentrations at one Trx concentration.

27. All the data (different peroxide and Trx concentrations) can be fit to the equation below using the multifunction nonlinear regression capabilities of a computer program such as Sigmaplot.

$$
\text { Rate }=\frac{k_{\mathrm{cat}} \cdot[\mathrm{Trx}] \cdot[\mathrm{ROOH}]}{\left(K_{\mathrm{m}}^{\mathrm{Trx}} \cdot[\mathrm{ROOH}]\right)+\left(K_{\mathrm{m}}^{\mathrm{ROOH}} \cdot[\mathrm{Trx}]\right)+([\mathrm{ROOH}] \cdot[\mathrm{Trx}])}
$$

Equation 7.10.2

These global fits will simultaneously calculate the $K_{\mathrm{m}}$ for $\operatorname{Trx}\left(K_{\mathrm{m}}^{\operatorname{Trx}}\right)$ and the $K_{\mathrm{m}}$ for peroxide $\left(K_{\mathrm{m}}^{\mathrm{ROOH}}\right)$, the $k_{\mathrm{cat}}$, and the errors associated with these constants. See Figure 7.10.2C for an example of a global fit using data obtained with Treponema pallidum AhpC using E. coli Trx and t-butyl hydroperoxide.

Alternatively, these $k_{\text {cat }}$ and $K_{m}$ values can be obtained using primary and secondary plots as described in Basic Protocol 1, steps 11 to 12 (Fig. 7.10.2A and B). Dalziel analysis has also been used to obtain similar rate constants for Prx proteins; for details refer to Baker et al. (2001), Jaeger et al. (2004), and Sayed and Williams (2004).

\section{MEASUREMENT OF SECOND-ORDER RATE CONSTANT WITH HYDROGEN PEROXIDE USING HORSERADISH PEROXIDASE (HRP) COMPETITION ASSAY}

This protocol describes an assay to determine the second-order rate constant for Prx reduction of peroxide by monitoring the enzyme's ability to compete with HRP (Fig. 7.10.5). HRP reacts with hydrogen peroxide to form compound I with a second-order rate constant of $1.8 \times 10^{7} \mathrm{M}^{-1} \mathrm{sec}^{-1}$ over a wide range of $\mathrm{pH}$ (Dolman et al., 1975). The formation of compound I can be measured spectroscopically as a decrease in absorbance at $403 \mathrm{~nm}$ $\left(\Delta \varepsilon_{403}=5.4 \times 10^{4} \mathrm{M}^{-1} \mathrm{~cm}^{-1}\right)$ (Dolman et al., 1975). When the hydrogen peroxide concentration is less than the HRP concentration, Prx activity can thus be detected as a function of the decreased formation of compound I (and thus decreased change in absorbance) as the Prx competes with HRP for the available peroxide. This assay monitors a partial turnover and provides a rate that is independent of the rate of reduction of the peroxidase - an advantage when the reductant is unknown or rate-limiting. Because HRP does not react efficiently with larger substrates such as cumene hydroperoxide and $t$-butyl hydroperoxide, this assay is only suitable for measuring the rate with hydrogen peroxide. As the Prx rate constant decreases, greater concentrations of Prx are required to efficiently compete with HRP; at higher protein concentrations, the assay becomes more technically difficult. We have found this assay most useful to analyze peroxidases with rate constants greater than $10^{5} \mathrm{M}^{-1} \mathrm{sec}^{-1}$. A similar assay with the much slower peroxidase, lignin peroxidase $\left(6.5 \times 10^{5} \mathrm{M}^{-1} \mathrm{sec}^{-1}\right)$, has been used to measure the second-order rate constant of Mycobacterium tuberculosis AhpE with hydrogen peroxide (Hugo et al., 2009). HRP competition has also been used to measure Prx reactivity with peroxynitrite (Trujillo et al., 2008). 


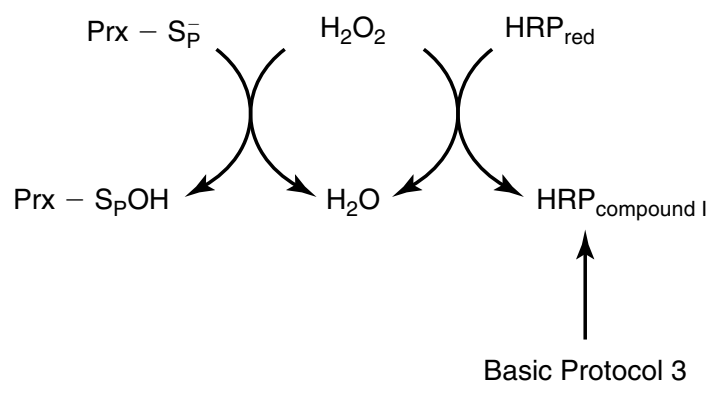

Figure 7.10.5 Determination of Prx activity by competition with horseradish peroxidase (HRP). As described in Basic Protocol 3, HRP is oxidized by $\mathrm{H}_{2} \mathrm{O}_{2}$ to form compound I, which can be monitored as a decrease in absorbance at $403 \mathrm{~nm}$. As reduced Prx (Prx- $\mathrm{S}_{\mathrm{P}}{ }^{-}$) reacts with $\mathrm{H}_{2} \mathrm{O}_{2}$ to form sulfenic acid (Prx- $\left.\mathrm{S}_{\mathrm{P}} \mathrm{OH}\right)$, less peroxide is available to oxidize HPR, resulting in a decrease in compound I formation.

\section{Materials}

$10 \mathrm{mM}$ hydrogen peroxide (see recipe)

HRP solution (see recipe)

Standard Prx buffer (see recipe)

Prereduced Prx (see Support Protocol 1)

100-mm Petri dishes

96-well UV-transparent half area plate (no lid required; 200 $\mu$ l well volume)

Plate reader spectrophotometer

\section{Create peroxide assay solution}

1. Dilute $100 \mu \mathrm{l}$ of $10 \mathrm{mM}$ hydrogen peroxide to $0.9 \mathrm{ml}$ in distilled water to make a 1 $\mathrm{mM}$ solution.

2. Add $180 \mu \mathrm{l}$ of the $1 \mathrm{mM}$ hydrogen peroxide to $3.82 \mathrm{ml}$ distilled water in a clean Petri dish $(100 \mathrm{~mm})$ to make $4 \mathrm{ml}$ of a $45 \mu \mathrm{M}$ hydrogen peroxide.

\section{Aliquot HRP and increasing concentrations of Prx into a 96-well plate}

3. To a row of wells, add $15 \mu \mathrm{M}$ HRP solution, six to eight different concentrations of prereduced Prx, and enough standard Prx buffer to make a final volume of $150 \mu \mathrm{l}$ (all concentrations are the final values after mixing). Be sure to include a set of samples with no Prx present (0). For each Prx concentration, include three to four replicates (a typical layout for an assay is shown in Figure 7.10.6). Carefully pipet up and down three to four times to mix, taking care to prevent the introduction of bubbles, which interfere with good absorbance measurements (existing bubbles can be popped using a clean $10-\mu$ l pipet tip).

For Prx proteins with a $k_{\text {cat }} / K_{m}$ for peroxide of $\sim 10^{7} \mathrm{M}^{-1} \mathrm{sec}^{-1}$ (for example, $S$. typhimurium AhpC; Parsonage et al., 2005), yeast TSA1 and 2 (Ogusucu et al., 2007), and Xylella fastidiosa PrxQ $\beta$ (Horta et al., 2010), suggested starting concentrations of Prx are: 0, 2, 4, 8, 12, and $16 \mu \mathrm{M}$. For Prxs with second-order rate constants of $10^{5}$ to $10^{6} \mathrm{M}^{-1} \mathrm{sec}^{-1}$, Prx concentrations will have to be increased. Concentrations of 0, 30, 60, 100, 150, and $200 \mu \mathrm{M}$ are suggested for a protein with a second-order rate constant of $\sim 2 \times 10^{5} \mathrm{M}^{-1} \mathrm{sec}^{-1}$ (unpublished data and Trujillo et al., 2007). As the Prx concentration increases, it becomes increasingly more difficult to prevent the formation of bubbles, and great care must be taken during pipetting and mixing.

\section{Determine the starting HRP absorbance}

4. Set up a plate reader to monitor absorbance in endpoint mode. Select a fixed wavelength of $403 \mathrm{~nm}$. In the case that a reference wavelength is requested, use $600 \mathrm{~nm}$. 
A

\begin{tabular}{|c|c|c|c|c|c|c|c|c|c|c|c|c|}
\hline & $\mathbf{1}$ & $\mathbf{2}$ & $\mathbf{3}$ & $\mathbf{4}$ & $\mathbf{5}$ & $\mathbf{6}$ & $\mathbf{7}$ & $\mathbf{8}$ & $\mathbf{9}$ & $\mathbf{1 0}$ & $\mathbf{1 1}$ & $\mathbf{1 2}$ \\
\hline $\mathrm{A}$ & 12 & 4 & 0 & 16 & 8 & 2 & 12 & 4 & 0 & 16 & 8 & 2 \\
\hline $\mathrm{B}$ & 12 & 4 & 0 & 16 & 8 & 2 & 12 & 4 & 0 & 16 & 8 & 2 \\
\hline $\mathrm{C}$ & & & & & & & & & & & & \\
\hline
\end{tabular}

B

\begin{tabular}{|l|c|c|c|c|c|c|c|c|c|c|c|c|}
\hline & $\mathbf{1}$ & $\mathbf{2}$ & $\mathbf{3}$ & $\mathbf{4}$ & $\mathbf{5}$ & $\mathbf{6}$ & $\mathbf{7}$ & $\mathbf{8}$ & $\mathbf{9}$ & $\mathbf{1 0}$ & $\mathbf{1 1}$ & $\mathbf{1 2}$ \\
\hline $\mathrm{A}$ & 20 & 4 & 0 & 15 & 8 & 2 & 12 & 18 & & & & \\
\hline $\mathrm{B}$ & 20 & 4 & 0 & 15 & 8 & 2 & 12 & 18 & & & & \\
\hline C & 20 & 4 & 0 & 15 & 8 & 2 & 12 & 18 & & & & \\
\hline $\mathrm{D}$ & 20 & 4 & 0 & 15 & 8 & 2 & 12 & 18 & & & & \\
\hline
\end{tabular}

Figure 7.10.6 Typical organization of a plate for HRP competition assay with six (A) and eight (B) Prx concentrations. Numbers in bold represent standard markings on a 96-well plate. Remaining numbers represent the Prx concentration in each well $(2$ to $20 \mu \mathrm{M})$. All wells contain $7.5 \mu \mathrm{M}$ HRP. Shaded areas represent sections of the plate to which hydrogen peroxide is added and HRP oxidation is measured at the same time. Each layout contains four replicates.

5. Measure absorbance for all wells at the same time.

\section{Measure change in HRP absorbance after addition of hydrogen peroxide in the presence of Prx}

Compound I is unstable; therefore, the change in absorbance at $403 \mathrm{~nm}$ should be measured within $90 \mathrm{sec}$ of peroxide addition.

6. Set the plate reader so that it only reads six to eight wells of a single row.

7. Using a multichannel pipettor, add $10 \mu \mathrm{l}$ of the $45 \mu \mathrm{M}$ hydrogen peroxide prepared in step 2 (final concentration of hydrogen peroxide, $3 \mu \mathrm{M}$ ) to one set of six to eight wells. Using a $200-\mu \mathrm{l}$ multichannel pipettor set at $100 \mu \mathrm{l}$, pipet up and down three times to mix solutions (being careful to minimize the creation of bubbles).

8. Read absorbance at $403 \mathrm{~nm}$ on the plate reader.

9. Change settings on the plate reader to read the next set of wells. Repeat steps 6 to 8 until all samples have been read.

\section{Calculate the Prx rate constant based upon competition with HRP}

The extent of inhibition of HRP oxidation $\left[\left(\Delta A_{\max }-\Delta A_{\mathrm{obs}}\right) / \Delta A_{\mathrm{obs}}\right]$ at each Prx concentration can be plotted against [Prx] in order to obtain the second-order rate constant for Prx $\left(k_{\operatorname{Prx}}\right)$ as established by Equation 7.10.3 (Winterbourn, 1987; Ogusucu et al., 2007):

$$
\left(\frac{\Delta A_{\max }-\Delta A_{\text {obs }}}{\Delta A_{\text {obs }}}\right)=\frac{k_{\text {AhpC }}[\mathrm{AhpC}]}{k_{\mathrm{HRP}}[\mathrm{HRP}]}
$$

\section{Equation 7.10.3}

10. Determine the change in absorbance $\left(\Delta A_{\text {obs }}\right)$ for each well by subtracting the absorbance after peroxide addition from the starting absorbance for the same well (Fig. 7.10.7A). To obtain $\Delta A_{\max }$, calculate the average change in HRP absorbance in the absence of Prx (average all 0 samples). 
A

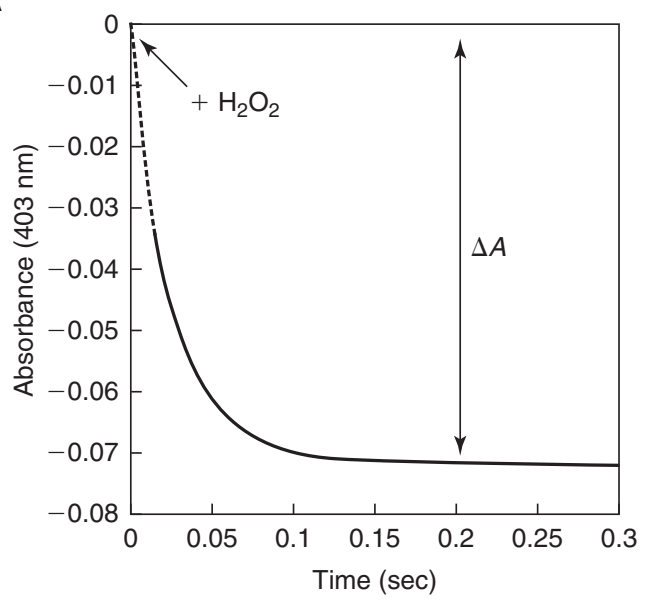

B

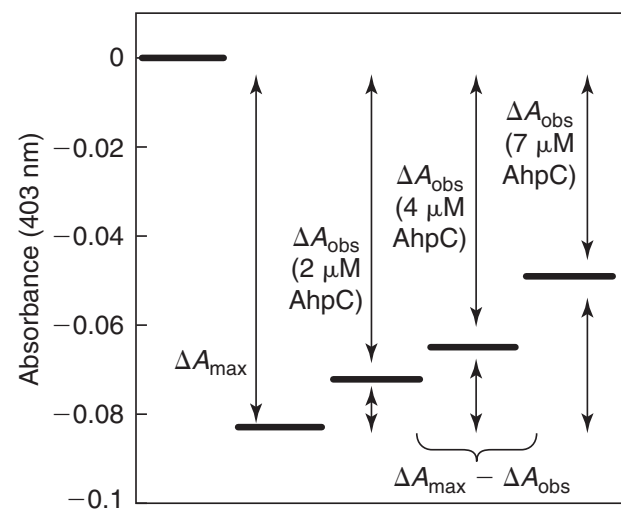

C

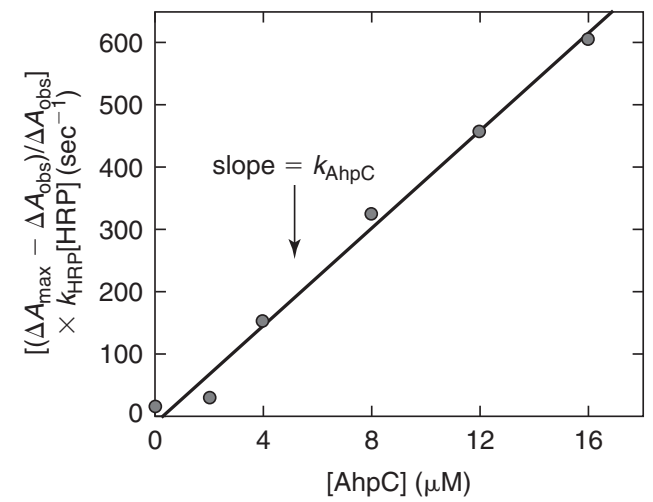

Figure 7.10.7 Prx inhibits the HRP reaction with hydrogen peroxide and can be used to measure the $k_{\mathrm{Prx}}$. (A) HRP absorbance at $403 \mathrm{~nm}$ decreases as compound I is formed in the presence of hydrogen peroxide. (B) As Prx concentrations increase, the amount of compound I formed decreases due to competition for the available peroxide. The relative amounts of hydrogen peroxide reacting with $\operatorname{HRP}\left(\Delta A_{\text {obs }}\right)$ and $\operatorname{Prx}\left(\Delta A_{\max }-\Delta A_{\text {obs }}\right)$ can be used to calculate the $k_{\text {app }}$ for each Prx concentration using Equation 7.10.3. (C) The values for $\left(\left(\Delta A_{\max }-\right.\right.$ $\left.\left.\Delta A_{\mathrm{obs}}\right) / \Delta A_{\mathrm{obs}}\right) \cdot k_{\mathrm{HRP}}[\mathrm{HRP}]$ are plotted versus [Prx] and fit by linear regression. The slope of the line provides the $k_{\mathrm{Prx}}$ for hydrogen peroxide. Shown are representative data for $7.5 \mu \mathrm{M} \mathrm{HRP}, 4 \mu \mathrm{M}$ hydrogen peroxide, and increasing concentrations of prereduced Salmonella typhimurium AhpC in $25 \mathrm{mM}$ potassium phosphate, $1 \mathrm{mM}$ EDTA, pH 7.0.

\section{Measurement of Peroxiredoxin Activity}

The fraction of peroxide reacted with HRP is proportional to the observed change in absorbance $\left(\Delta A_{o b s}\right)$.

The fraction of peroxide reacted with Prx and not HRP is proportional to the difference between the observed absorbance change and the maximal absorbance change observed in the absence of $\operatorname{Prx}\left(\Delta A_{\max }-\Delta A_{\text {obs }}\right)($ Fig. 7.10.7B).

11. Calculate $k_{\text {hrp }}$ [HRP] [( $\left.\left.\Delta A_{\max }-\Delta A_{\mathrm{obs}}\right) / \Delta A_{\mathrm{obs}}\right]$ for each well using a second-order rate constant of $1.7 \times 10^{7} \mathrm{M}^{-1} \mathrm{sec}^{-1}$ for the reaction of HRP with hydrogen peroxide and an HRP concentration of $7.5 \mu \mathrm{M}$ (Dolman et al., 1975).

12. Plot all values for $k_{\mathrm{hrp}}[\mathrm{HRP}]\left[\left(\Delta A_{\max }-\Delta A_{\mathrm{obs}}\right) / \Delta A_{\mathrm{obs}}\right]$ ( $y$ axis) against Prx concentration ( $x$ axis) and fit to a linear equation.

The slope of the line gives the second-order rate constant for Prx reacting with hydrogen peroxide (Fig. 7.10.7C). As Prx concentrations increase, the percent of peroxide left to react with HRP approaches 0 and the slope of the line will start to flatten out; only the linear portion of the line should be used to calculate the Prx second-order rate constant.

\subsubsection{4}




\section{MEASUREMENT OF THE CATALYTIC CYSTEINE pK $_{\mathrm{a}}$ USING THE HRP COMPETITION ASSAY}

The HRP competition assay has been successfully used to determine the $\mathrm{pK}_{\mathrm{a}}$ of the catalytic cysteine for Prx proteins including S. typhimurium AhpC (Nelson et al., 2008), yeast TSA1 and TSA2 (Ogusucu et al., 2007), and X. fastidiosa PrxQ $\beta$ (Horta et al., 2010). For these experiments, the second-order rate constants are obtained across a range of $\mathrm{pH}$ values, then the values for $k_{\mathrm{Prx}}$ are plotted against $\mathrm{pH}$ and used to calculate a $\mathrm{pK}_{\mathrm{a}}$ for the Prx. More detailed procedures are provided in Nelson (2008) and Ogusucu (2007). For this analysis, it is helpful that $k_{\mathrm{HRP}}$ does not change across a wide range of $\mathrm{pH}$ values from 5 to 10 . For $\mathrm{pH}<5$, the $k_{\mathrm{HRP}}$ in step 13 will need to be replaced with a corrected value that can be calculated for each $\mathrm{pH}$ using the equation provided by Dunford (1999), or determined directly by stopped-flow spectroscopic analysis.

\section{MEASUREMENT OF PEROXIDASE ACTIVITY USING FOX ASSAY TO MEASURE PEROXIDE DISAPPEARANCE}

The assay described in this section directly monitors decreasing peroxide concentrations (Fig. 7.10.8) in the presence of Fe(II) and xylenol orange. Under acidic conditions, peroxides are able to oxidize $\mathrm{Fe}$ (II) to $\mathrm{Fe}(\mathrm{III})$, which forms a complex with xylenol orange [o-cresolsulfonphthalein-3,3-bis(methyliminodiacetic acid sodium salt)]; the production of this complex causes the generation of a blue-purple color with $\varepsilon_{560}$ of $1.5 \times 10^{4} \mathrm{M}^{-1}$ $\mathrm{cm}^{-1}$ (Wolff, 1994). This assay is suitable for hydrogen peroxide, cumene hydroperoxide, and $t$-butyl hydroperoxide, as well as lipid peroxides. It can be used to measure peroxide concentrations as low as $10 \mu \mathrm{M}$ up to the $\mathrm{mM}$ range. Prx peroxidase activity can be measured under partial- or single-turnover conditions, under steady-state conditions in the presence of Trx and TrxR (or other appropriate physiological reductants), or using DTT as the reductant. This protocol uses DTT as a reductant; however, we note that this chemical reductant can be much slower than the physiological reductant (Horta et al., 2010), and, at higher concentrations $(\sim 1 \mathrm{mM})$, DTT can directly react with the peroxide. While the FOX assay is useful when a reductant is unknown, in our hands it is also much noisier and less sensitive than the assays described in Basic Protocols 1 to 3. This assay is most useful for peroxidases with rate constants less than $10^{5} \mathrm{M}^{-1} \mathrm{sec}^{-1}$; for Prxs with rates on the order of $10^{7} \mathrm{M}^{-1} \mathrm{sec}^{-1}$, the reaction is completed in a couple of seconds and the $K_{\mathrm{m}}$ tends to be lower than the detectable limit of the assay.

\section{Materials}

FOX Reagent A (see recipe)

FOX Reagent B (see recipe)

$10 \mathrm{mM}$ peroxide substrate: hydrogen peroxide (see recipe), cumene hydroperoxide (see recipe), or tert-butyl hydroperoxide (see recipe)

Standard Prx buffer (see recipe)

Pure Prx protein

$100 \mathrm{mM}$ DTT (see recipe)

Spectrophotometer

\section{Make FOX working reagent}

1. Mix 1 volume FOX reagent A with 100 volumes FOX reagent B. For example, for 20 samples, use $0.2 \mathrm{ml}$ FOX Reagent A and $20 \mathrm{ml}$ FOX Reagent B. Make fresh daily.

Make enough FOX working reagent to have $1 \mathrm{ml}$ for each sample.

\section{Make standard curve}

2. Create a series of samples containing the peroxide of interest at known concentrations. 


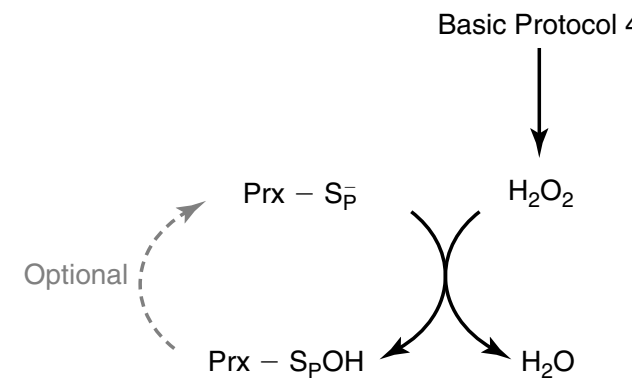

Figure 7.10.8 Determination of Prx activity using the FOX asay to measure $\mathrm{H}_{2} \mathrm{O}_{2}$ disappearance as reduced $\operatorname{Prx}\left(\operatorname{Prx}-\mathrm{S}_{\mathrm{P}}{ }^{-}\right)$is oxidized to sulfenic acid $\left(\mathrm{Prx}-\mathrm{S}_{\mathrm{P}} \mathrm{OH}\right)$. As described in Basic Protocol 4, the concentration of $\mathrm{H}_{2} \mathrm{O}_{2}$ is measured over time based on its ability to oxidize $\mathrm{Fe}(\mathrm{II})$ to $\mathrm{Fe}(\mathrm{III})$.

At least six concentrations should be used between $10 \mu M$ and $200 \mu M$ peroxide. Standards should include controls containing no peroxide and two to three replicates for each standard concentration. Standard volumes should be the same as the volumes used for the samples.

\section{Start Prx reaction}

3. Set up peroxidase assays in microcentrifuge tubes containing $5 \mu \mathrm{M}$ Prx, $100 \mu \mathrm{M}$ DTT (add from $100 \mathrm{mM}$ stock; optional), and peroxide concentrations ranging from 10 to $200 \mu \mathrm{M}$. Set up peroxidase reactions in microcentrifuge tubes containing $5 \mu \mathrm{M}$ Prx, $100 \mu$; DTT (optional; add from $100 \mathrm{mM}$ stock), and peroxide concentrations ranging from 10 to $200 \mu \mathrm{M}$ in standard Prx buffe.

The final assay volume will be based on the number of timepoints to be measured (55 $\mu l$ $\times$ number of timepoints $=$ total assay volume $)$.

Under these conditions, DTT is used to reduce the Prx protein and allows for multiple turnovers. For all assays including DTT, be sure to include controls containing DTT and peroxide but no Prx. For single-turnover reactions, the amount of Prx should be increased so that the amount of peroxide reduced in one turnover is sufficient to provide a reliably detectable change in peroxide (e.g., $100 \mu \mathrm{M}$ peroxide to $10 \mu \mathrm{M}$ prereduced Prx, see Support Protocol 1).

\section{Measure peroxide concentration}

4. Quench each sample at the appropriate time by removing $50 \mu \mathrm{l}$ of sample from the assay and adding it to $950 \mu \mathrm{l}$ of FOX working reagent.

This reagent is acidic and will stop the reaction since the protonated catalytic cysteine is unable to act as a nucleophile and reduce peroxides at low $\mathrm{pH}$.

The volume can be adjusted according to the amount of test sample and the volumes required for the spectrophotometer or plate reader to be used. To use a plate reader, we typically add $200 \mu \mathrm{l}$ of FOX working reagent to $20 \mu \mathrm{l}$ of sample in microcentrifuge tubes and then transfer $200 \mu \mathrm{l}$ of the developed solution to a 96-well plate. All volumes should be held constant between the samples and the standards.

5. Vortex each sample and incubate at room temperature for a minimum of $30 \mathrm{~min}$ to allow the absorbance to stabilize.

Once developed, the absorbance is stable for up to $24 \mathrm{hr}$.

6. Read the absorbance at $560 \mathrm{~nm}$ of standards and samples. Plot the standard curve and use a linear fit to calculate the peroxide concentration for each sample.

Measurement of Peroxiredoxin Activity

7. Plot the peroxide concentration ( $y$ axis) versus time ( $x$ axis) and find the initial rate by linear regression of the earliest points, which should fall on a straight line. 
Sorbitol can be omitted from FOX Reagent B (see Reagents and Solutions) if the concentration of peroxide is high $(>100 \mu \mathrm{M})$, because the role of sorbitol is to amplify the signal. With peroxide concentrations higher than $100 \mu \mathrm{M}$, the amount of reaction mix added to the FOX working reagent in step 4 should be decreased to 10 to $20 \mu \mathrm{l}$; just ensure that the points in the standard curve are treated the same way as the sample to be measured.

\section{MEASUREMENT OF PEROXIDASE ACTIVITY IN VIVO USING FOX ASSAY}

With some small adaptations, the FOX assay can be used with live bacteria to compare strains with Prx knockouts to the wild-type strain. It is also possible to compare mutant protein to the wild-type by over-expressing both. For these assays, we do not recommend using hydrogen peroxide as the substrate, since multiple proteins use this substrate, including catalase and glutathione peroxidase. In contrast, cumene hydroperoxide, $t$ butyl hydroperoxide, and linoleic acid hydroperoxide are much more efficiently reduced by peroxiredoxins than by other peroxidases and have been used with some success to monitor intracellular Prx activity in Xanthomonas campestris (Vattanaviboon et al., 2002; Klomsiri et al., 2005).

\section{Materials}

Bacterial expression vector containing Prx gene

Bacterial growth medium: LB (e.g., UNIT 9.9) or other medium of choice)

FOX Reagent A (see recipe)

FOX Reagent B (see recipe)

$10 \mathrm{mM}$ peroxide substrate: cumene hydroperoxide (see recipe), $t$-butyl hydroperoxide (see recipe), or linoleic acid hydroperoxide (see recipe)

Spectrophotometer

Flasks for bacterial growth

Additional reagents and equipment for transformation of bacteria with plasmids (Seidman et al., 1997)

\section{Transform bacterial strain with Prx expression plasmid}

1. Transform the desired bacterial strain with an expression plasmid containing the coding region for the Prx of choice using standard methods (Seidman et al., 1997). At the same time, transform a different sample of the same strain with an empty vector to provide a negative control. Plate cells using an appropriate antibiotic for the vector to select for cells containing the plasmid.

2. Take cells from each plate and inoculate tubes containing $5 \mathrm{ml}$ bacterial growth medium with either the Prx vector or the control vector. Incubate overnight with shaking at $37^{\circ} \mathrm{C}$.

\section{Prepare FOX working reagent}

3. Mix 1 volume FOX reagent A with 100 volumes FOX reagent B. For example, for 20 samples, use $0.2 \mathrm{ml} \mathrm{FOX} \mathrm{Reagent} \mathrm{A} \mathrm{and} 20 \mathrm{ml}$ FOX Reagent B. Make fresh daily.

Make enough FOX working reagent to have $1 \mathrm{ml}$ for each sample.

\section{Treat cells with peroxide}

4. Measure absorbance of overnight cultures at $600 \mathrm{~nm}$. Add enough of each overnight culture to separate flasks containing $20 \mathrm{ml}$ growth medium to give a final $A_{600}$ of 0.1 .

5. Grow samples for $4 \mathrm{hr}$ (they should still be in log-phase growth) with shaking at $37^{\circ} \mathrm{C}$ and measure $A_{600}$. Adjust absorbance of each sample to 0.5 using fresh medium.

Assessment of the Activity of Antioxidant Enzymes

7.10.17 
6. Add cumene hydroperoxide, $t$-butyl hydroperoxide, or linoleic acid hydroperoxide to a final concentration of $200 \mu \mathrm{M}$.

7. For cumene hydroperoxide (dissolved in DMSO) or linoleic acid hydroperoxide (dissolved in methanol), be sure to include a control where the cells are treated with an equivalent volume of the solvent and no peroxide.

\section{Create standard curve}

8. To create a standard curve, add different concentrations of peroxide to $0.5 \mathrm{ml}$ fresh medium to yield final peroxide concentrations ranging from 10 to $200 \mu \mathrm{M}$.

\section{Measure residual hydroperoxide concentrations}

9. At 5-min intervals, remove $1 \mathrm{ml}$ of the culture and centrifuge for $3 \mathrm{~min}$ at $10,000 \times$ $g, 4^{\circ} \mathrm{C}$ or room temperature.

10. Add $100 \mu \mathrm{l}$ of the cleared supernatant to $900 \mu \mathrm{l}$ of FOX working reagent and incubate for at least $30 \mathrm{~min}$ at room temperature.

11. Read the absorbance at $560 \mathrm{~nm}$ of standard curve and samples. Plot the standard curve and calculate peroxide concentration in samples as described in Basic Protocol 4, steps 5 to 7.

SUPPORT PROTOCOL 1

\section{Measurement of Peroxiredoxin Activity}

\subsubsection{8}

\section{PREREDUCTION OF Prx OR Trx PROTEINS}

Some of the protocols described in this chapter require at least one of the proteins to be fully reduced at the start of each assay. Prx proteins are commonly oxidized after prolonged exposure to air. In our hands, various Prxs and Trx will remain fully reduced for up to $6 \mathrm{hr}$ on ice after removal of DTT; however, auto-oxidation may be a problem with other proteins and situations. In this case, reduced proteins can be stored in the presence of bead-linked TCEP (immobilized TCEP disulfide reducing gel, from Thermo Scientific). In this case, the sample is centrifuged immediately prior to each assay and protein removed from the top of the beads.

\section{Materials}

Purified Prx or Trx protein $(\sim 10 \mathrm{mg} / \mathrm{ml})$

$100 \mathrm{mM}$ DTT stock

PD-10 desalting column (GE Healthcare)

Suitable buffer for desired assay: Prx reaction buffer (see recipe) or standard Prx buffer (see recipe)

Spectrophotometer

1. Thaw purified protein. Add $1 / 10$ volume DTT from a $100 \mathrm{mM}$ stock to the protein solution (i.e., for $1 \mathrm{ml}$ protein, add $0.1 \mathrm{ml} \mathrm{DTT}$ ). To ensure complete reduction, incubate Prx for $1 \mathrm{hr}$ at room temperature. Alternatively, incubate overnight at $4^{\circ} \mathrm{C}$.

It is desirable to have at least a 20-fold molar excess of DTT over protein. If the protein is more concentrated than $10 \mathrm{mg} / \mathrm{ml}$, the final DTT concentration should be increased accordingly.

2. Remove DTT using a PD-10 desalting column.

a. First, equilibrate the column with $25 \mathrm{ml}$ of buffer.

b. Load protein.

As much as $2.5 \mathrm{ml}$ of protein may be loaded on the column, but better separation is achieved with smaller volumes. 
c. After protein has completely loaded onto the column, add buffer to make a total of $2.5 \mathrm{ml}$. Add another $0.5 \mathrm{ml}$ buffer and collect the resulting eluate in a microcentrifuge tube.

d. When no more eluate flows from the column, add another $0.5 \mathrm{ml}$ buffer to the column, collect the resulting eluate in a new microcentrifuge tube, and repeat for a total of 10 fractions.

3. Measure the 280-nm absorbance of each aliquot in a spectrophotometer. Combine those fractions containing the peak of the $A_{280}$ absorbance.

DTT will start to elute towards the end of the peak, so only include the main portion of the peak and do not include the tail end.

4. Determine the concentration of the combined fractions. When an extinction coefficient is known, it is preferable to measure absorbance, which can be converted to concentration using Beer's law: $A=\varepsilon_{280} c l$ where $c=$ concentration $(\mathrm{M})$ and $l=$ path length $(\mathrm{cm})$.

Otherwise, a protein assay such as the BCA Assay (Pierce) can be used (also see APPENDIX 3I).

In our hands, reduced Prxs and Trxs have been successfully stored on ice for $6 \mathrm{hr}$ without a loss of reduced cysteine. This time may vary for other proteins and in other locations. The number of reduced cysteines remaining in the original sample can be determined at the end of the assay by measuring the number of cysteines available to react with DTNB (see Support Protocol 2).

Note that this support protocol will typically result in a $>2$-fold dilution of protein from its original concentration. If higher concentrations of prereduced Prx are required for the subsequent assay, Prxs should be concentrated in the presence of DTT prior to removal of this reductant using a small-volume ultrafiltration device such as an Amicon Ultra-4 $m L$ or Ultra-0.5 $m L$ (Millipore).

\section{MEASUREMENT OF THIOL CONTENT BY REACTION WITH DTNB}

In the presence of free thiols, 5,5'-dithiobis(2-nitrobenzoate) (DTNB, also referred to as Ellman's reagent) undergoes a disulfide rearrangement to produce a mixed disulfide between the target thiol and 2-nitro-5-thiobenzoate (TNB) and release a free TNB molecule. This reaction is stoichiometric, with one molecule of free TNB produced per molecule of free thiol. The absorbance of free TNB at $412 \mathrm{~nm}$ is used to calculate the original thiol concentration. The protocol here employs denaturing conditions to allow for accessibility to all protein thiols.

\section{Materials}

Guanidine buffer (see recipe)

$30 \mathrm{mM}$ 5,5'-dithiobis(2-nitrobenzoic acid) (DTNB) in DMSO

Prereduced Prx protein with DTT removed (see Support Protocol 1)

1. Set up a spectrophotometer to read absorbance at $412 \mathrm{~nm}$. Add enough guanidine buffer to a cuvette to make up a final volume of $1 \mathrm{ml}$ after addition of DTNB and Prx.

2. Add $5 \mu \mathrm{l}$ of $30 \mathrm{mM}$ DTNB, mix, and measure absorbance at $412 \mathrm{~nm}$ after 2 to $5 \mathrm{~min}$ to determine spontaneous TNB production.

3. Add Prx and measure absorbance at $412 \mathrm{~nm}$. Subtract out background production measured in step 2 and calculate the number of reduced thiols using $\varepsilon_{412}=14,150$ $\mathrm{M}^{-1} \mathrm{~cm}^{-1}$.

DTT will reduce DTNB and should be removed prior to the assay.

Assessment of the Activity of Antioxidant Enzymes

7.10.19 
SUPPORT PROTOCOL 3
Sulfenic acids react with TNB to form a mixed disulfide, resulting in a decrease in absorbance at $412 \mathrm{~nm}$ (Poole and Ellis, 2002; UNIT 17.12), and thus interfere with the correct quantification of protein thiols. Prereduction with DTT as described in Support Protocol 1 will reduce sulfenic acids. Alternately, sulfenic acids can be blocked prior to DTNB analysis (Poole and Ellis, 2002; UNIT 17.12).

\section{MEASUREMENT OF PEROXIDE CONCENTRATION}

While hydrogen peroxide concentrations can be measured using the $\mathrm{H}_{2} \mathrm{O}_{2}$ absorbance at $240 \mathrm{~nm}\left(\varepsilon_{240}=43.6 \mathrm{M}^{-1} \mathrm{~cm}^{-1}\right)$ or by monitoring HRP oxidation (Poole and Ellis, 2002), these methods are not suitable for other peroxides. The method described here can quickly be used to measure an accurate concentration for all peroxide substrates under very similar conditions to those used for subsequent Prx assays.

\section{Materials}

Prx reaction buffer (see recipe)

Purified E. coli $\operatorname{Trx}(500 \mu \mathrm{M}$ diluted into Prx reaction buffer)

Purified E. coli TrxR (50 $\mu \mathrm{M}$ diluted into Prx reaction buffer)

Peroxiredoxin $(50 \mu \mathrm{M}$ diluted into Prx reaction buffer)

$15 \mathrm{mM}$ NADPH (dissolved in $10 \mathrm{mM}$ Tris $\cdot \mathrm{SO}_{4} \mathrm{pH} 8.5$ )

$10 \mathrm{mM}$ peroxide solution to be measured: cumene hydroperoxide (see recipe) or $t$-butyl hydroperoxide (see recipe)

Spectrophotometer

1-ml semi-micro quartz cuvettes

1. Turn on the spectrophotometer and allow it to warm up and become stable ( $\sim 30 \mathrm{~min}$ ). Set the spectrophotometer to kinetics mode with a wavelength of $340 \mathrm{~nm}$.

2. In a 1-ml quartz cuvette, mix $950 \mu \mathrm{l}$ Prx reaction buffer, $10 \mu \mathrm{l}$ Trx, $10 \mu \mathrm{l}$ TrxR, and $10 \mu \mathrm{l}$ of a $50 \mu \mathrm{M}$ Prx solution.

Final concentrations in the assay should be $5 \mu M \operatorname{Trx}, 0.5 \mu M \operatorname{Prx}$, and $0.5 \mu M \operatorname{Tr} x$.

3. Add $10 \mu \mathrm{l}$ of $15 \mathrm{mM}$ NADPH; the final concentration is $150 \mu \mathrm{M}$, and the $A_{340}$ should be $\sim 0.9$. Mix the contents and begin recording the 340-nm absorbance.

This value will provide the background activity in the absence of peroxide $(\sim 1 \mathrm{~min})$. Make sure that no more than $10 \%$ of the NADPH is used up at this step.

4. Add $10 \mu \mathrm{l}$ of peroxide solution to start the assay (100 $\mu \mathrm{M}$ peroxide final concentration). Monitor the change in absorbance at $340 \mathrm{~nm}$ until the absorbance remains constant or returns to the rate of change before the peroxide addition, indicating that all of the peroxide has been reduced.

Ensure that some NADPH remains, so that the extent of the reaction is limited by the peroxide concentration.

5. Calculate the difference in absorbance before and after the addition of peroxide and convert this value to $\mu \mathrm{M}$ NADPH consumed using $\varepsilon_{340}=6,220 \mathrm{M}^{-1} \mathrm{~cm}^{-1}$; this is equal to the amount of peroxide added to the reaction.

\section{REAGENTS AND SOLUTIONS}

Use Milli-Q-purified water or equivalent in all recipes and protocol steps. For common stock solutions, see APPENDIX 2A; for suppliers, see SUPPLIERS APPENDIX.

\section{Cumene hydroperoxide, $10 \mathrm{mM}$}

Dilute cumene hydroperoxide into DMSO to make a $100 \mathrm{mM}$ stock (for an $80 \%$ purity solution, this will be a $\sim 60$-fold dilution). Add $100 \mu \mathrm{l}$ of the $100 \mathrm{mM}$ stock to

continued 
$0.9 \mathrm{ml}$ standard Prx buffer to make a $10 \mathrm{mM}$ solution. Confirm the concentration of the $10 \mathrm{mM}$ solution using Support Protocol 3. Make the $10 \mathrm{mM}$ peroxide solution fresh daily.

For all assays using this substrate, control reactions should be done to make sure the solvent does not affect Prx activity. This can best be accomplished by measuring hydrogen peroxide-dependent activity with and without DMSO present in the assay at the largest final concentration required for the desired set of cumene hydroperoxide assays.

\section{Dithiothreitol (DTT), $100 \mathrm{mM}$}

Dissolve $0.154 \mathrm{~g}$ dithiothreitol (DTT) per $10 \mathrm{ml}$ distilled water. Aliquots of $100 \mathrm{mM}$ DTT $(200 \mu \mathrm{leach})$ can be stored at $-80^{\circ} \mathrm{C}$ for up to 1 year. Once thawed, use each aliquot within $10 \mathrm{hr}$ and do not refreeze.

\section{FOX Reagent A}

Dissolve ferrous ammonium sulfate in $2.5 \mathrm{M}$ sulfuric acid $\left(\mathrm{H}_{2} \mathrm{SO}_{4}\right)$ for a final concentration of $25 \mathrm{mM}$. The iron salt must be dissolved directly in acid because ferrous ions are prone to autoxidation at physiological $\mathrm{pH}$. This solution can be stored for several weeks at $4^{\circ} \mathrm{C}$.

\section{FOX Reagent $B$}

Dissolve sorbitol for a final concentration of $100 \mathrm{mM}$ and xylenol orange for a final concentration of $125 \mu \mathrm{M}$ in distilled water. This solution can be stored for 1 week at $4^{\circ} \mathrm{C}$.

\section{Guanidine buffer}

$50 \mathrm{mM}$ Tris $\cdot \mathrm{Cl}, \mathrm{pH} 8.0$ (APPENDIX 2A)

$4 \mathrm{M}$ guanidine hydrochloride

$0.5 \mathrm{mM}$ disodium EDTA, pH 8.0 (APPENDIX 2A)

Store up to 1 year at room temperature

\section{HRP solution}

Type VI horseradish peroxidase can be purchased from Sigma (cat. no. P8375). Dissolve HRP in standard Prx buffer (see recipe) to an approximate concentration of $0.5 \mathrm{mM}$. The final HRP concentration should be confirmed by measuring $A_{403}$ of the stock solution and using an $\varepsilon_{403}$ of $1.02 \times 10^{5} \mathrm{M}^{-1} \mathrm{~cm}^{-1}$ (Dolman et al., 1975; Dunford, 1999). Once dissolved, aliquots of HRP can be stored at $-80^{\circ} \mathrm{C}$ for up to 1 month. Multiple freeze-thaw cycles should be avoided

\section{Hydrogen peroxide, $10 \mathrm{mM}$}

The concentration of the $30 \%$ hydrogen peroxide solution $(\sim 8.8 \mathrm{M})$ should be confirmed by measuring the $240-\mathrm{nm}$ absorbance of a 1000-fold dilution (perform a 50 -fold dilution followed by a 20-fold dilution) and using an $\varepsilon_{240}$ of $43.6 \mathrm{M}^{-1} \mathrm{~cm}^{-1}$. Add $\sim 114 \mu \mathrm{l}$ of a $30 \%$ hydrogen peroxide solution to a graduated cylinder and make up to $100 \mathrm{ml}$ with distilled water to obtain a $10 \mathrm{mM} \mathrm{H}_{2} \mathrm{O}_{2}$ solution. Prepare fresh daily.

\section{Linoleic acid hydroperoxide, $10 \mathrm{mM}$}

This substrate is not commercially available and should be prepared by enzymatic oxidation of linoleic acid with soybean lipoxygenase as described in Evans et al. (1998). Using this method, small volumes of linoleic acid hydroperoxide will be prepared in methanol and the concentration will have to be determined by the absorbance at $234 \mathrm{~nm}\left(\varepsilon_{234}=25,000 \mathrm{M}^{-1} \mathrm{~cm}^{-1}\right)$. Once the concentration has been determined, dilute the solution in methanol to a final concentration of $10 \mathrm{mM}$.

Assessment of the Activity of Antioxidant Enzymes

7.10.21 


\section{Prx reaction buffer}

$25 \mathrm{mM}$ potassium phosphate, $\mathrm{pH} 7.0$ (APPENDIX 2A)

$1 \mathrm{mM}$ disodium EDTA

$100 \mathrm{mM}$ ammonium sulfate

Store up to 1 year at room temperature

\section{Standard Prx buffer}

$25 \mathrm{mM}$ potassium phosphate, $\mathrm{pH} 7.0$ (APPENDIX 2A)

1 mM EDTA

Store up to 1 year at room temperature

\section{t-Butyl hydroperoxide, $10 \mathrm{mM}$}

Tert-butyl hydroperoxide $(90.12 \mathrm{~g} / \mathrm{ml})$ can be purchased from multiple sources as a $70 \%$ solution in water. $(\sim 7.7 \mathrm{M})$. Dilute this into standard Prx buffer (see recipe) to make a $1 \mathrm{mM}$ solution (130 $\mu \mathrm{l}$ of $70 \%$ t-butyl hydroperoxide and $870 \mu \mathrm{l}$ buffer). Make a 10-fold dilution ( $100 \mu \mathrm{l}$ of $1 \mathrm{mM} t$-butyl hydroperoxide and $900 \mu \mathrm{l}$ standard Prx buffer) to make a $100 \mu \mathrm{M}$ solution. Finally, make one more 10-fold dilution of the $100 \mu \mathrm{M}$ solution to obtain the $10 \mathrm{mM}$ solution. Confirm the concentration of the $10 \mathrm{mM}$ solution using Support Protocol 3. Prepare fresh daily.

\section{COMMENTARY}

\section{Background Information}

Peroxiredoxin enzymes contain an absolutely conserved active-site cysteine, referred to as the peroxidatic cysteine $\left(\mathrm{C}_{\mathrm{P}}\right)$, which reacts with peroxide to form a cysteine sulfenic acid (R-SOH) and releases water or the corresponding alcohol (Hall et al., 2010). In contrast to the peroxide reduction reaction common to all Prxs, regeneration of the reduced, active form of these enzymes varies. In many Prxs, a second cysteine, referred to as the resolving cysteine $\left(\mathrm{C}_{\mathrm{R}}\right)$, attacks the R-SOH to form a water molecule and a disulfide bond in the protein. In the typical 2-Cys Prxs, arguably the earliest Prx group to be recognized, the $C_{R}$ is found in the $C$-terminus of the partner subunit, yielding an intersubunit disulfide bond upon oxidation. As more examples of Prxs were discovered, the $C_{R}$ participating in the recycling process was recognized to reside in other positions, where it generally forms an intrasubunit disulfide bond (atypical 2-Cys Prxs). In 1-Cys Prxs, there is no $\mathrm{C}_{\mathrm{R}}$, and a thiol from another protein or small molecule presumably takes the place of this residue in the recycling process. While the $C_{R}$ shows up in different locations within the structure, formation of a disulfide bond with the $C_{P}$ always involves localized unfolding of the structure around both cysteines (Hall et al., 2010). Prxs are typically reduced by a thiol-containing disulfide reductase system that utilizes a CXXC-containing oxidoreductase domain or protein [e.g., thioredoxin (Trx),
AhpF, AhpD or glutaredoxin (Grx)] as the direct reductant, which is in turn reduced by a flavin-containing, $\mathrm{NAD}(\mathrm{P}) \mathrm{H}$-dependent disulfide reductase component (Poole, 2005). The mechanism for reduction of the $C_{P}$ in some of the 1-Cys Prx proteins is still unclear. Other features that vary across Prxs include their peroxide specificity and susceptibility towards inactivation by high peroxide concentrations, their oligomeric state, and their subcellular localization.

More recent bioinformatic and structural analysis has resulted in the identification of 6 subfamilies designated as AhpC/Prx1, Prx6, BCP/PrxQ, Tpx, Prx5, and AhpE. Prx proteins are widely distributed, and subfamily distributions for Prxs are frequently not correlated with their phylogenetic distribution. For example, T. pallidum contains one highly expressed Prx similar to the prototypical AhpC protein from $S$. typhimurium. In contrast, Treponema denticola has only one Prx, but this protein is more similar to the Homo sapiens Prx6 protein (Parsonage et al., 2010a). Humans express six different Prx proteins from three different subfamilies (Knoops et al., 2007), while Escherichia coli contains three different Prxs from three different subfamilies (Baker and Poole, 2003). Much remains to be learned about why multiple Prx proteins are needed in a given organism, although mice with knockouts to either Prx1 or Prx2 (which are both found in the cytoplasm and share high sequence and structural similarity) have been 
shown to exhibit different defects (Lee et al., 2003; Neumann et al., 2003).

\section{Critical Parameters}

Because of differences among different Prx proteins, some prior research will have to be done to determine how best to assay Prx activity. Important assay components that vary greatly depending on the Prx to be measured include selection of the peroxide substrate, substrate concentration, and Prx reductant. Many of these choices are aided by some preliminary work to identify the genetic context, subfamily, and which of the previously studied Prxs is most similar to the Prx of interest.

Prx subfamily: Within a single Prx subfamily, there is frequently still variation with respect to substrate specificity, sensitivity to hyperoxidation, and mechanism of disulfide formation; however, identification of the correct subfamily is still a very useful way to identify the most appropriate starting assay parameters for a given Prx. More information about the Prx subfamilies can be found in UNIT 7.9, as well as in Nelson et al. (2011) and Hall et al. (2010). An online database tool is also available that provides a putative subfamily assignment for over 6,000 Prx sequences found in GenBank(nr) (http://www.csb.wfu.edu/prex/) (Soito et al., 2010).

Reductants: Most Prxs are reduced in the cell by a thiol-containing disulfide reductase system typically composed of a CXXCcontaining oxidoreductase domain or protein (e.g., Trx) as the direct reductant working in concert with a flavin-containing disulfide reductase component (e.g., TrxR) which is reduced by NAD(P)H (Poole, 2005). Although Trx is the most common reductant, some Prxs utilize another disulfide reductase such as AhpF, AhpD, or glutaredoxin (Grx). AhpF contains an $\mathrm{N}$-terminal domain that interacts with AhpC and a C-terminal TrxR-like flavincontaining domain. For those Prxs that use $\mathrm{AhpF}$ as reductant, as well as those linked to AhpD (all bacterial typical 2-Cys proteins belonging to the AhpC/Prx1 subfamily), the $a h p F$ or $a h p D$ coding sequence is located immediately downstream of the $a h p C$ sequence (Bryk et al., 2002; Poole, 2005). Trx is generally the best starting choice as a general Prx reductant, and protocols using Trx are provided in Basic Protocols 1 and 2 (Trx can also be used as a reductant for the assay described in Basic Protocol 4 after leaving out DTT). In the NADPH-linked assay described in Basic Protocol 1, the rate of turnover is frequently limited by the ability of Prx to be reduced by Trx. This limitation has been dealt with to some degree in Basic Protocol 2, in which a large excess of reduced Trx is added and monitored directly. In all the protocols described, AhpF can replace Trx and TrxR when appropriate (details provided in Alternate Protocol 2 and the introduction to Basic Protocol 2).

In the absence of a resolving Cys, 1-Cys members of the BCP subfamily have been shown to be reduced by Trx or Grx (Rouhier et al., 2004; Clarke et al., 2010). Further information about how to best perform a Grxlinked Prx assay can be found in Parsonage et al. (2010b) and (Rouhier et al., 2004). The mechanism for reduction of the $C_{P}$ in 1-Cys members of the Prx6 subfamily is still unclear. Trx is able to reduce Saccharomyces cerevisiae Ahp1p (Pedrajas et al., 2000), but not human PrxVI (Kang et al., 1998). Other potential reductants include GST $\pi$ and glutathione (Manevich et al., 2004), glutaredoxin (Pedrajas et al., 2010), and ascorbate (Monteiro et al., 2007). The assays described in Basic Protocol 3, Basic Protocol 4, and Alternate Protocol 3 can be used to measure rates of Prx oxidation by peroxide in the absence of any information about the reductant.

\section{Peroxide substrates}

Peroxide concentrations should be chosen carefully, as some (mostly eukaryotic) members of the AhpC/Prx1 subfamily are hyperoxidized at high peroxide concentration to form sulfinic $\left(-\mathrm{S}_{\mathrm{P}} \mathrm{O}_{2} \mathrm{H}\right)$ and sulfonic $\left(-\mathrm{S}_{\mathrm{P}} \mathrm{O}_{3} \mathrm{H}\right)$ acids. These species are not reducible by Trx or DTT, although in eukaryotes the sulfinic acid form of some Prxs can be rescued by an ATP-dependent repair enzyme called sulfiredoxin (Lowther and Haynes, 2010).

Members of the AhpC/Prx1 subfamily have been shown to react very efficiently with hydrogen peroxide $\left(\sim 10^{7} \mathrm{M}^{-1} \mathrm{sec}^{-1}\right)$. S. typhimurium AhpC prefers hydrogen peroxide to more bulky peroxides such as cumene hydroperoxide and $t$-butyl hydroperoxide (Parsonage et al., 2008).

E. coli Tpx (in contrast to AhpC) is more specific for cumene hydroperoxide (a bulky, hydrophobic substrate) than for hydrogen peroxide $\left(K_{\mathrm{m}}\right.$ of $9 \mu \mathrm{M}$ compared with $1.7 \mathrm{mM}$, respectively; Baker and Poole, 2003). Other Tpx proteins have also been shown to react with alkyl hydroperoxides, suggesting that members of the Tpx subfamily are important for
Assessment of the Activity of Antioxidant Enzymes

7.10.23 
lipid hydroperoxide removal in bacteria (Cha et al., 2004, Jaeger et al., 2004).

Human PrxV is somewhat less reactive with hydrogen peroxide than PrxI and PrxII, but is very efficient with organic hydroperoxides and peroxynitrite (Trujillo et al., 2007).

Less information is available for the BCP subfamily. The current data suggest that many of the enzymes in this subfamily react with similar specificities with a variety of peroxides including hydrogen peroxide, cumene hydroperoxide, $t$-butyl hydroperoxide, and linoleic acid hydroperoxide (Jeong et al., 2000; Horta et al., 2010).

\section{Troubleshooting}

\section{Inactivation of Prxs by peroxide}

While eukaryotic Prx1 and 2 are more prone to over-oxidation than many of the bacterial members of the same subfamily, most Prxs can be hyperoxidized and thus inactivated at high peroxide concentrations. Inactivation is best observed when the assays described in Basic Protocol 1 are allowed to proceed through multiple turnovers until NADPH and/or hydrogen peroxide consumption is complete. Under conditions where Prx is inactivated, the decrease in NADPH quickly becomes nonlinear in the absence of peroxide or where NADPH exhaustion has occurred. Turnover appears to be a critical component for inactivation to occur (Baker and Poole, 2003). Example data showing peroxide-dependent inactivation of Prxs can be found for human Prx1 (Yang et al., 2002), S. typhimurium AhpC (Wood et al., 2003), and E. coli Tpx (Baker and Poole, 2003). Because of this, peroxide concentrations should be selected to minimize the occurrence of hyperoxidation. Starting concentrations around $100 \mu \mathrm{M}$ are generally safe, but this should be confirmed experimentally.

In some cases, Prxs may become inactivated during purification. It is possible to confirm the presence of a full complement of reducible cysteines using a DTNB assay (see Support Protocol 2). This is particularly a problem for proteins in which the resolving cysteine has been mutated. If a Prx is inactivated during purification, the inclusion of $1 \mathrm{mM}$ DTT in all buffers used for purification can generally circumvent the problem.

\section{Nonsaturating kinetics}

Some Prxs appear not to follow MichaelisMenten kinetics and show no saturation with peroxide and/or Trx (Baker et al., 2001; Sayed and Williams, 2004). This might suggest that the $K_{\mathrm{m}}$ for the nonsaturable substrate is so high that the rate is linearly proportional to substrate concentration under technically feasible conditions. In this case, kinetic parameters can be calculated using the integrated Dalziel rate equation to calculate kinetic parameters analogous to maximum velocity and $K_{\mathrm{m}}$ for peroxide (Forstrom et al., 1979).

It should be noted that an N-terminally Histagged T. pallidum AhpC exhibited nonsaturable kinetics with Trx. Without the tag, this protein interacted in a saturable manner with Trx and also had a lower $K_{\mathrm{m}}$ and higher $V_{\max }$ with various peroxides than the tagged protein (Parsonage et al., 2010a). Oligomerization and activity of human PrxIII was also altered by the presence of a tag (Cao et al., 2007). We suggest purifying Prxs without a tag or, at the very least, cleaving the tag prior to kinetic analysis.

\section{Anticipated Results}

Although it is expected that kinetic analysis of various Prx proteins will reveal the presence of a peroxidase activity under some conditions, there is almost certainly going to be considerable variability in the details of this activity among different Prx family members. Of the Prxs measured to date, second-order rate constants for the reaction with peroxide have varied between $10^{4}$ (Hugo et al., 2009) and $10^{8} \mathrm{M}^{-1} \mathrm{sec}^{-1}$ (Manta et al., 2009). Even among members of the same Prx subfamily in the same organism, peroxide substrate specificity and sensitivity toward hyperoxidation can vary substantially (Cox et al., 2009; Sayed and Williams, 2004).

\section{Time Considerations}

For all these protocols, the time required to accomplish the assays is secondary to the time required to obtain the appropriate purified proteins. We also suggest that sufficient time be allotted for multiple repeats of all the assays to ensure the reproducibility of the data prior to publication.

All solutions can be prepared the day before unless stated otherwise.

For all assays, data analysis will take some time, but is often done on a day subsequent to performing the assays. All datasets should be analyzed prior to performing the next replicate to ensure that the assay does not need to be modified.

Basic Protocol 1 and Alternate Protocol 1: Using a Prx with typical activity, these assays can be carried out in a half-day. An enzyme 
displaying low activity would need longer assays, and hence more time is required to complete the set of experiments.

Basic Protocol 2: A complete bi-substrate kinetic analysis using this procedure can be completed in 1 day. Assume that between 2 and $4 \mathrm{hr}$ will be spent preparing the solutions and the stopped flow instrument for the assays. Incubating the Trx with DTT overnight at $4{ }^{\circ} \mathrm{C}$ shortens the preparation time required on the day of the assays. It is frequently preferable to only use one Trx concentration the first day, to provide time for optimization of the correct range of peroxide concentrations and to familiarize oneself with the assays.

Basic Protocol 3: Allow 2 to $3 \mathrm{hr}$ to reduce the Prx and to prepare protein and peroxide solutions. Incubating the Prx with DTT overnight at $4{ }^{\circ} \mathrm{C}$ shortens the preparation time required on the day of the assays. The time required to aliquot samples in the plate and read the results will vary depending on the number of samples to be assayed. Allow $1 \mathrm{hr}$ total for 24 samples and $\sim 2 \mathrm{hr}$ to prepare and $\sim 1.5 \mathrm{hr}$ to read two 96-well plates.

Basic Protocol 4: FOX working reagent should be prepared the day of the assay; other solutions can be prepared before. Under these conditions, Prxs should utilize all of the peroxide within the first 1 to $10 \mathrm{~min}$. Although each sample must be incubated at least $30 \mathrm{~min}$ with the working reagent before reading the absorbance, the final product is stable, allowing samples quenched at various times to all be read together.

\section{Acknowledgments}

This work was supported by funding from the National Institutes of Health [F32 GM074537 to K.J.N. and RO1 GM050389 to L.B.P]. We thank Dr. Chananat Klomsiri and Dr. Stacey Reeves for their advice in preparing this manuscript.

\section{Literature Cited}

Baker, L.M. and Poole, L.B. 2003. Catalytic mechanism of thiol peroxidase from Escherichia coli. Sulfenic acid formation and overoxidation of essential CYS61. J. Biol. Chem. 278:9203-9211.

Baker, L.M., Raudonikiene, A., Hoffman, P.S., and Poole, L.B. 2001. Essential thioredoxindependent peroxiredoxin system from Helicobacter pylori: Genetic and kinetic characterization. J. Bacteriol. 183:1961-1973.

Bryk, R., Lima, C.D., Erdjument-Bromage, H., Tempst, P., and Nathan, C. 2002. Metabolic enzymes of mycobacteria linked to antioxidant defense by a thioredoxin-like protein. Science 295:1073-1077.
Cao, Z., Bhella, D., and Lindsay, J.G. 2007. Reconstitution of the mitochondrial PrxIII antioxidant defence pathway: General properties and factors affecting PrxIII activity and oligomeric state. J. Mol. Biol. 372:1022-1033.

Cha, M.K., Kim, W.C., Lim, C.J., Kim, K., and Kim, I.H. 2004. Escherichia coli periplasmic thiol peroxidase acts as lipid hydroperoxide peroxidase and the principal antioxidative function during anaerobic growth. J. Biol. Chem. 279:8769-8778.

Clarke, D.J., Ortega, X.P., Mackay, C.L., Valvano, M.A., Govan, J.R., Campopiano, D.J., Langridge-Smith, P., and Brown, A.R. 2010. Subdivision of the bacterioferritin comigratory protein family of bacterial peroxiredoxins based on catalytic activity. Biochemistry 49:13191330.

Cornish-Bowden, A. 2004. Fundamentals of Enzyme Kinetics. Portland Press Ltd., London.

Cox, A.G., Pearson, A.G., Pullar, J.M., Jonsson, T.J., Lowther, W.T., Winterbourn, C.C., and Hampton, M.B. 2009. Mitochondrial peroxiredoxin 3 is more resilient to hyperoxidation than cytoplasmic peroxiredoxins. Biochem. J. 421:51-58.

Cox, A.G., Winterbourn, C.C., and Hampton, M.B. 2010. Mitochondrial peroxiredoxin involvement in antioxidant defence and redox signalling. Biochem. J. 425:313-325.

Dietz, K.J., Jacob, S., Oelze, M.L., Laxa, M., Tognetti, V., de Miranda, S.M., Baier, M., and Finkemeier, I. 2006. The function of peroxiredoxins in plant organelle redox metabolism. $J$. Exp. Bot. 57:1697-1709.

Dolman, D., Newell, G.A., and Thurlow, M.D. 1975. A kinetic study of the reaction of horseradish peroxidase with hydrogen peroxide. Can. J. Biochem. 53:495-501.

Dunford, H.B. 1999. Spectroscopy of horseradish peroxidase. I. Optical, resonance raman, magnetic circular dichroism, x-ray absorption, and diffraction. In Heme peroxidases (Dunford, H.B. eds.) pp 135-174. John Wiley \& Sons, Hoboken, N.J.

Evans, M.V., Turton, H.E., Grant, C.M., and Dawes, I.W. 1998. Toxicity of linoleic acid hydroperoxide to Saccharomyces cerevisiae: Involvement of a respiration-related process for maximal sensitivity and adaptive response. J. Bacteriol. 180:483-490.

Forstrom, J.W., Stults, F.H., and Tappel, A.L. 1979. Rat liver cytosolic glutathione peroxidase: Reactivity with linoleic acid hydroperoxide and cumene hydroperoxide. Arch. Biochem. Biophys. 193:51-55.

Hall, A., Nelson, K.J., Poole, L.B., and Karplus, P.A. 2010. Structure-based insights into the catalytic power and conformational dexterity of peroxiredoxins. Antioxid. Redox Signal. 402:194-209.

Holmgren, A. and Reichard, P. 1967. Thioredoxin 2: Cleavage with cyanogen bromide. Eur. J. Biochem. 2:187-196.
Assessment of the Activity of Antioxidant Enzymes

7.10 .25 
Horta, B.B., de Oliveira, M.A., Discola, K.F., Cussiol, J.R., and Netto, L.E. 2010. Structural and biochemical characterization of peroxiredoxin Qbeta from Xylella fastidiosa: Catalytic mechanism and high reactivity. J. Biol. Chem. 285:16051-16065.

Hugo, M., Turell, L., Manta, B., Botti, H., Monteiro, G., Netto, L.E., Alvarez, B., Radi, R., and Trujillo, M. 2009. Thiol and sulfenic acid oxidation of AhpE, the one-cysteine peroxiredoxin from Mycobacterium tuberculosis: Kinetics, acidity constants, and conformational dynamics. Biochemistry 48:94169426.

Jaeger, T., Budde, H., Flohe, L., Menge, U., Singh, M., Trujillo, M., and Radi, R. 2004. Multiple thioredoxin-mediated routes to detoxify hydroperoxides in Mycobacterium tuberculosis. Arch. Biochem. Biophys. 423:182-191.

Jeong, W., Cha, M.K., and Kim, I.H. 2000. Thioredoxin-dependent hydroperoxide peroxidase activity of bacterioferritin comigratory protein (BCP) as a new member of the thiol-specific antioxidant protein (TSA)/Alkyl hydroperoxide peroxidase C (AhpC) family. J. Biol. Chem. 275:2924-2930.

Kang, S.W., Baines, I.C., and Rhee, S.G. 1998. Characterization of a mammalian peroxiredoxin that contains one conserved cysteine. J. Biol. Chem. 273:6303-6311.

Kang, S.W., Rhee, S.G., Chang, T.S., Jeong, W., and Choi, M.H. 2005. 2-Cys peroxiredoxin function in intracellular signal transduction: Therapeutic implications. Trends Mol. Med. 11:571-578.

Klomsiri, C., Panmanee, W., Dharmsthiti, S., Vattanaviboon, P., and Mongkolsuk, S. 2005. Novel roles of ohrR-ohr in Xanthomonas sensing, metabolism, and physiological adaptive response to lipid hydroperoxide. J. Bacteriol. 187:3277-3281.

Knoops, B., Loumaye, E., and Van Der Eecken, V. 2007. Evolution of the peroxiredoxins. In Peroxiredoxin Systems (Flohé, L. and Harris, J.R. eds.) pp. 27-40. Springer, New York.

Krause, G. and Holmgren, A. 1991. Substitution of the conserved tryptophan 31 in Escherichia coli thioredoxin by site-directed mutagenesis and structure-function analysis. J. Biol. Chem. 266:4056-4066.

Lee, T.H., Kim, S.U., Yu, S.L., Kim, S.H., Park do, S., Moon, H.B., Dho, S.H., Kwon, K.S., Kwon, H.J., Han, Y.H., Jeong, S., Kang, S.W., Shin, H.S., Lee, K.K., Rhee, S.G., and Yu, D.Y. 2003. Peroxiredoxin II is essential for sustaining life span of erythrocytes in mice. Blood 101:50335038.

Lennon, B.W. and Williams, C.H. Jr. 1995. Effect of pyridine nucleotide on the oxidative halfreaction of Escherichia coli thioredoxin reductase. Biochemistry 34:3670-3677.

Lowther, W.T. and Haynes, A.C. 2010. Reduction of cysteine sulfinic acid in eukaryotic, typical 2-Cys peroxiredoxins by sulfiredoxin. Antioxid. Redox Signal. 15:99109.
Manevich, Y., Feinstein, S.I., and Fisher, A.B. 2004. Activation of the antioxidant enzyme 1-CYS peroxiredoxin requires glutathionylation mediated by heterodimerization with pi GST. Proc. Natl. Acad. Sci. U.S.A. 101:3780-3785.

Manta, B., Hugo, M., Ortiz, C., Ferrer-Sueta, G., Trujillo, M., and Denicola, A. 2009. The peroxidase and peroxynitrite reductase activity of human erythrocyte peroxiredoxin 2. Arch. Biochem. Biophys. 484:146-154.

Monteiro, G., Horta, B.B., Pimenta, D.C., Augusto, O., and Netto, L.E. 2007. Reduction of 1-Cys peroxiredoxins by ascorbate changes the thiolspecific antioxidant paradigm, revealing another function of vitamin C. Proc. Natl. Acad. Sci. U. S. A. 104:4886-4891.

Nelson, K.J., Parsonage, D., Hall, A., Karplus, P.A., and Poole, L.B. 2008. Cysteine pK(a) values for the bacterial peroxiredoxin AhpC. Biochemistry 47:12860-12868.

Nelson, K.J., Knutson, S.T., Soito, L., Klomsiri, C., Poole, L.B., and Fetrow, J.S. 2011. Analysis of the peroxiredoxin family: Using active site structure and sequence information for global classification and residue analysis. Proteins 79:947-964.

Neumann, C.A., Krause, D.S., Carman, C.V., Das, S., Dubey, D.P., Abraham, J.L., Bronson, R.T., Fujiwara, Y., Orkin, S.H., and Van Etten, R.A. 2003. Essential role for the peroxiredoxin $\operatorname{Prdx} 1$ in erythrocyte antioxidant defence and tumour suppression. Nature 424:561-565.

Ogusucu, R., Rettori, D., Munhoz, D.C., Soares Netto, L.E., and Augusto, O. 2007. Reactions of yeast thioredoxin peroxidases I and II with hydrogen peroxide and peroxynitrite: Rate constants by competitive kinetics. Free Radic. Biol. Med. 42:326-334.

Parsonage, D., Youngblood, D.S., Sarma, G.N., Wood, Z.A., Karplus, P.A., and Poole, L.B. 2005. Analysis of the link between enzymatic activity and oligomeric state in $\mathrm{AhpC}$, a bacterial peroxiredoxin. Biochemistry 44:10583-10592.

Parsonage, D., Karplus, P.A., and Poole, L.B. 2008. Substrate specificity and redox potential of AhpC, a bacterial peroxiredoxin. Proc. Natl. Acad. Sci. U.S.A. 105:82098214.

Parsonage, D., Desrosiers, D.C., Hazlett, K.R., Sun, Y., Nelson, K.J., Cox, D.L., Radolf, J.D., and Poole, L.B. 2010a. Broad specificity AhpC-like peroxiredoxin and its thioredoxin reductant in the sparse antioxidant defense system of Treponema pallidum. Proc. Natl. Acad. Sci. U.S.A. 107:6240-6245.

Parsonage, D., Reeves, S.A., Karplus, P.A., and Poole, L.B. 2010b. Engineering of fluorescent reporters into redox domains to monitor electron transfers. Methods Enzymol. 474:1-21.

Pedrajas, J.R., Miranda-Vizuete, A., Javanmardy, N., Gustafsson, J.A., and Spyrou, G. 2000. Mitochondria of Saccharomyces cerevisiae contain one-conserved cysteine type peroxiredoxin with thioredoxin peroxidase activity. J. Biol. Chem. 275:16296-16301. 
Pedrajas, J.R., Padilla, C.A., McDonagh, B., and Barcena, J.A. 2010. Glutaredoxin participates in the reduction of peroxides by the mitochondrial 1-CYS peroxiredoxin in Saccharomyces cerevisiae. Antioxid. Redox Signal. 13:249-258.

Peskin, A.V., Low, F.M., Paton, L.N., Maghzal, G.J., Hampton, M.B., and Winterbourn, C.C. 2007. The high reactivity of peroxiredoxin 2 with $\mathrm{H}_{2} \mathrm{O}_{2}$ is not reflected in its reaction with other oxidants and thiol reagents. J. Biol. Chem. 282:11885-11892.

Poole, L.B. 2005. Bacterial defenses against oxidants: Mechanistic features of cysteine-based peroxidases and their flavoprotein reductases. Arch. Biochem. Biophys. 433:240-254.

Poole, L.B. 2007. The catalytic mechanism of peroxiredoxins. In Peroxiredoxin Systems (L. Flohé, and J.R. Harris, eds.) pp. 61-81. Springer, New York.

Poole, L.B. and Ellis, H.R. 1996. Flavin-dependent alkyl hydroperoxide reductase from Salmonella typhimurium. 1. Purification and enzymatic activities of overexpressed AhpF and AhpC proteins. Biochemistry 35:56-64.

Poole, L.B. and Ellis, H.R. 2002. Identification of cysteine sulfenic acid in AhpC of alkyl hydroperoxide reductase. Methods Enzymol. 348:122-136.

Poole, L.B., Godzik, A., Nayeem, A., and Schmitt, J.D. 2000. AhpF can be dissected into two functional units: Tandem repeats of two thioredoxinlike folds in the $\mathrm{N}$-terminus mediate electron transfer from the thioredoxin reductase-like Cterminus to AhpC. Biochemistry 39:6602-6615.

Rabilloud, T., Heller, M., Gasnier, F., Luche, S., Rey, C., Aebersold, R., Benahmed, M., Louisot, P., and Lunardi, J. 2002. Proteomics analysis of cellular response to oxidative stress: Evidence for in vivo overoxidation of peroxiredoxins at their active site. J. Biol. Chem. 277:1939619401.

Rengby, O., Cheng, Q., Vahter, M., Jörnvall, H., and Arnér, E.S. 2009. Highly active dimeric and lowactivity tetrameric forms of selenium-containing rat thioredoxin reductase 1. Free Radic. Biol. Med. 46:893-904.

Rouhier, N., Gelhaye, E., Gualberto, J.M., Jordy, M.N., De Fay, E., Hirasawa, M., Duplessis, S., Lemaire, S.D., Frey, P., Martin, F., Manieri, W., Knaff, D.B., and Jacquot, J.P. 2004. Poplar peroxiredoxin Q. A thioredoxin-linked chloroplast antioxidant functional in pathogen defense. Plant Physiol. 134:1027-1038.

Sayed, A.A. and Williams, D.L. 2004. Biochemical characterization of 2-Cys peroxiredoxins from Schistosoma mansoni. J. Biol. Chem. 279:26159-26166.

Seaver, L.C. and Imlay, J.A. 2001. Alkyl hydroperoxide reductase is the primary scavenger of endogenous hydrogen peroxide in Escherichia coli. J. Bacteriol. 183:7173-7181.

Seidman, C.E., Struhl, K., Sheen, J., and Jessen, T. 1997. Introduction of plasmid DNA into cells. Curr. Protoc. Mol. Biol. 37:1.8.1-1.8.10.
Soito, L., Williamson, C., Knutson, S.T., Fetrow, J.S., Poole, L.B., and Nelson, K.J. 2010. PREX: PeroxiRedoxin classification indEX, a database of subfamily assignments across the diverse peroxiredoxin family. Nucleic Acids Res. 39:D332D337.

Trujillo, M., Clippe, A., Manta, B., Ferrer-Sueta, G., Smeets, A., Declercq, J.P., Knoops, B., and Radi, R. 2007. Pre-steady state kinetic characterization of human peroxiredoxin 5: Taking advantage of Trp84 fluorescence increase upon oxidation. Arch. Biochem. Biophys. 467:95-106.

Trujillo, M., Ferrer-Sueta, G., and Radi, R. 2008. Kinetic studies on peroxynitrite reduction by peroxiredoxins. Methods Enzymol. 441:173196.

Vattanaviboon, P., Whangsuk, W., Panmanee, W., Klomsiri, C., Dharmsthiti, S., and Mongkolsuk, S. 2002. Evaluation of the roles that alkyl hydroperoxide reductase and $\mathrm{Ohr}$ play in organic peroxide-induced gene expression and protection against organic peroxides in Xanthomonas campestris. Biochem. Biophys. Res. Commun. 299:177-182.

Veal, E.A., Day, A.M., and Morgan, B.A. 2007. Hydrogen peroxide sensing and signaling. Mol. Cell 26:1-14.

Winterbourn, C.C. 1987. The ability of scavengers to distinguish $\mathrm{OH}$-production in the ironcatalyzed Haber-Weiss reaction: Comparison of four assays for OH. Free Radic. Biol. Med. 3:3339.

Winterbourn, C.C. 2008. Reconciling the chemistry and biology of reactive oxygen species. Nat. Chem. Biol. 4:278-286.

Wolff, S.P. 1994. Ferrous ion oxidation in presence of ferric ion indicator xylenol orange for measurement of hydroperoxides. Methods Enzymol. 233:182-189.

Wollman, EE, d'Auriol, L, Rimsky, L, Shaw, A, Jacquot, JP, Wingfield, P, Graber, P, Dessarps, F, Robin, P, Galibert, F, Bertoglio, J., and Didier Fradelizi, D. 1988. Cloning and espression of a cDNA for human thioredoxin. J. Biol. Chem. 263:15506-15512.

Wood, Z.A., Poole, L.B., and Karplus, P.A. 2001. Structure of intact AhpF reveals a mirrored thioredoxin-like active site and implies large domain rotations during catalysis. Biochemistry 40:3900-3911.

Wood, Z.A., Poole, L.B., and Karplus, P.A. 2003. Peroxiredoxin evolution and the regulation of hydrogen peroxide signaling. Science 300:650653.

Yang, K.S., Kang, S.W., Woo, H.A., Hwang, S.C., Chae, H.Z., Kim, K., and Rhee, S.G. 2002. Inactivation of human peroxiredoxin I during catalysis as the result of the oxidation of the catalytic site cysteine to cysteine-sulfinic acid. J. Biol. Chem. 277:38029-38036.

Zhang, B., Su, Y., Ai, G., Wang, Y., Wang, T., and Wang, F. 2005. Involvement of peroxiredoxin I in protecting cells from radiation-induced death. J. Radiat. Res. (Tokyo) 46:305-312.
Assessment of the Activity of Antioxidant Enzymes

7.10.27 


\section{Key References}

Fourquet, S., Huang, M.E., D'Autreaux, B. and Toledano, M.B. 2008. The dual functions of thiol-based peroxidases in $\mathrm{H}_{2} \mathrm{O}_{2}$ scavenging and signaling. Antioxid. Redox Signal. 10:15651576.

Review of biochemical and kinetic properties of peroxiredoxins and the related family of glutathione peroxidases.

Hall, A., Nelson, K.J., Poole, L.B., Karplus, P.A. 2010. Structure-based insights into the catalytic power and conformational dexterity of peroxiredoxins. Antioxid. Redox Signal. 402:194-209.

Review of Prx function and subfamily with an emphasis on structural characteristics.

\section{Internet Resources}

http://www.csb.wfu.edu/prex/

PREX is a searchable database containing $>6,000$ Prx protein sequences unambiguously classified into one of six distinct subclasses. Subfamily classifications use information around the active sites of structurally characterized subfamily members to search for sequences with conserved functionallyrelevant motifs (Nelson et al., 2011, Soito et al., 2010).

\section{Measurement of Peroxiredoxin Activity}

7.10.28 